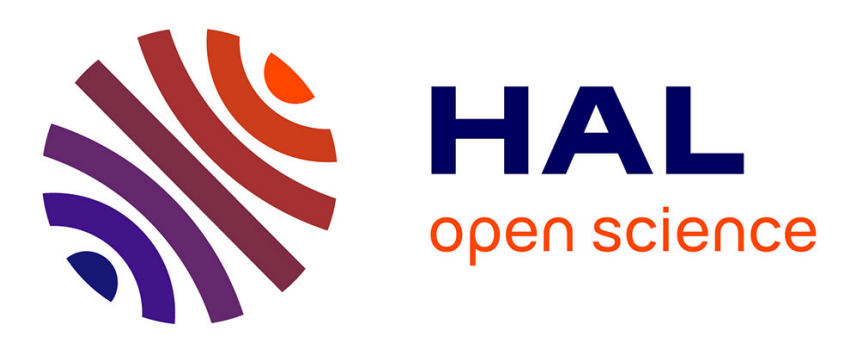

\title{
The Role of Health at Birth and Parental Investment in Early Child Development. Evidence from the French ELFE Cohort
}

\author{
Emmanuelle Lavaine, Marion Davin
}

\section{- To cite this version:}

Emmanuelle Lavaine, Marion Davin. The Role of Health at Birth and Parental Investment in Early Child Development. Evidence from the French ELFE Cohort. 2021. hal-03189147

\author{
HAL Id: hal-03189147 \\ https://hal.inrae.fr/hal-03189147
}

Preprint submitted on 2 Apr 2021

HAL is a multi-disciplinary open access archive for the deposit and dissemination of scientific research documents, whether they are published or not. The documents may come from teaching and research institutions in France or abroad, or from public or private research centers.
L'archive ouverte pluridisciplinaire HAL, est destinée au dépôt et à la diffusion de documents scientifiques de niveau recherche, publiés ou non, émanant des établissements d'enseignement et de recherche français ou étrangers, des laboratoires publics ou privés.

\section{(1) (1) $\$$}

Distributed under a Creative Commons Attribution - NonCommercial - NoDerivatives| 4.0 


\title{
The Role Of Health At Birth And Parental Investment In Early Child Development. Evidence From The French ELFE Cohort.*
}

\author{
Marion Davin ${ }^{\dagger} \quad$ Emmanuelle Lavaine ${ }^{\ddagger}$
}

March 2021

\begin{abstract}
This paper combines a theoretical and an empirical approach to address how health at birth affects child development? Using a simple theoretical model in which parents invest in their children, we identify the mechanisms through which better health at birth can improve child development. We also emphasise how parental socioeconomic status can shape the effects of health at birth. We perform an empirical analysis on a French cohort of children born in 2011, using a unique dataset ELFE. We identify the effect of birth weight and gestational age on child development at one year. The results indicate that only gestational age positively affects early development. We find no empirical evidence for the existence of a severity effect, according to which the adverse effects of poor health at birth are higher for children in low-income families or with poorly educated mothers.
\end{abstract}

Keywords: Early Child Development, Health at birth, Parental investment

JEL classification: C26; I14; I18

${ }^{*}$ The ELFE survey is a joint project between the French Institute for Demographic Studies (INED) and the National Institute of Health and Medical Research (INSERM), in partnership with the French blood transfusion service (Etablissement français du sang, EFS), Santé publique France, the National Institute for Statistics and Economic Studies (INSEE), the Direction générale de la santé (DGS, part of the Ministry of Health and Social Affairs), the Direction générale de la prévention des risques (DGPR, Ministry for the Environment), the Direction de la recherche, des études, de l'évaluation et des statistiques (DREES, Ministry of Health and Social Affairs), the Département des études, de la prospective et des statistiques (DEPS, Ministry of Culture), and the Caisse nationale des allocations familiales (CNAF), with the support of the Ministry of Higher Education and Research and the Institut national de la jeunesse et de l'éducation populaire (INJEP). Via the RECONAI platform, it receives a government grant managed by the National Research Agency under the "Investissements d'avenir" programme (ANR-11-EQPX-0038).

${ }^{\dagger}$ CEE-M, Univ. Montpellier, CNRS, INRAE, SupAgro, Montpellier, France. Email: marion.davin@umontpellier.fr

${ }^{\ddagger}$ CEE-M, Univ. Montpellier, CNRS, INRAE, SupAgro, Montpellier, France. Email: emmanuelle.lavaine@umontpellier.fr 


\section{Introduction}

It is well documented in the economic literature that investment in early childhood is the most powerful investment a country can make, given its long term economic return and its opportunity to improve the distribution of human capital among agents.1 The identification of human capital determinants remains a desirable proposition in the economic literature. Indeed, human capital plays a vital role in an individual's income potential and, as emphasised by Manuelli and Seshadri (2014), plays a central role in determining the wealth of nations and their level of development.2 Early child development is a priority of WHO and UNICEF's work. The Commission on the first 1000 days of the child, launched in September 2019 by the French President, illustrates the importance of recognising the determinants of early child development in the design of efficient policy tools. This will lead to a better understanding of the mechanisms through which inequalities may be formed at an early age.

In this study, we focussed on health at birth as a determinant of early childhood development. The economic mechanisms linking these two elements and how the relationship between health at birth and early childhood development may differ between low and highincome groups, are not well documented in the literature. No data on France's situation is available due to the lack of large-scale studies. Data from the recent French Longitudinal Study of Children, ELFE - a rich cohort data set of children born in 2011 in France - fill the literature gap. We examined how health at birth affects French children's cognitive development at a very early age and how this effect differs between socio-economic groups. We addressed this question by adopting an economic approach. More specifically, we adopted a theoretical and empirical approach to identify the impact of birth weight and gestational age on child development at the age of one year. In particular, we considered optimising parents' behaviours to theoretically assess the effect of health at birth on child development and to examine how a family's socio-economic status can influence the relationship. We

\footnotetext{
${ }^{1}$ Currie and Almond (2011a) provides a survey of empirical works that emphasise the long-term consequences for human capital of events occurring before age five. The concept of dynamics complementarity presented in Cunha and Heckman (2007), according to which the return on investment during childhood increases with early child development, provides an explanation.

${ }^{2}$ The Manuelli and Seshradi' paper attempted to explain the income differences between countries. They focussed on the human capital in each country and provided a new way to measure it. They found that crosscountry differences in average human capital per worker were much larger than that suggested by previous studies. They concluded that a large part of the cross-country differences in wealth could be explained by differences in human capital quality.
} 
also considered a non-random assignment of health at birth when conducting the empirical analysis.

From an empirical point of view, the positive correlation between health at birth and child development is well documented (see e.g. Maggi et al., 2010). Moreover, the literature provides strong evidence that poor initial health negatively impacts the first few years of elementary school (Figlio et al. 2014), reduces academic outcomes from childhood to early adolescence (Bharadwaj et al., 2018), and negatively affects adult health and skills development outcomes (Almond and Currie, 2011b; Almond et al., 2018). Some authors also used rich cohort data sets to examine the effects of health at birth on child development. For example, Jefferis et al. (2002) emphasised the negative effect of low birth weight on cognitive development at different ages in the UK. The authors, however, did not examine the different economic mechanisms that may link health at birth and child development. In the literature, evidence for very early childhood is scarce. Hence we have little information on the potential effects of policy interventions in ameliorating this disadvantage during early life, especially in France ${ }^{3}$

The literature on child development reveals that childhood's socioeconomic environment is crucial. In particular, it appears that the income gap in households with children translates into relative disadvantage early in life by affecting child development before age five (see e.g. Almond et al. 2018, who provide an explanation on how human capital develops during the early years.) Focussing on the interplay between health and family environment, part of the literature attempts to examine if poor health conditions affect children's development differentially across socioeconomic groups. There is no clear consensus emerging from the studies. Case et al. (2002) examined health outcomes in the US and found that the negative health impact of chronic health conditions in early life is more pronounced in low-income families. In contrast, Currie and Stabile (2003) found that the effect of a health shock on Canadian children's test scores and future health does not differ across socioeconomic groups. A recent study of Wei and Feeny (2019) confirmed this result. Authors found no evidence that Canadian children from low-income families suffered more from poor health at birth than those of high-income families. In the UK, no evidence was found that social background modified the effect of birth weight on cognitive development Jefferis et al.

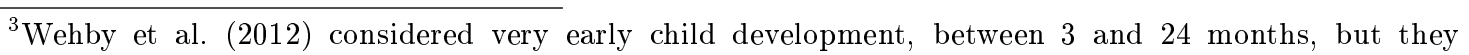
focussed on parental and household investment effects, not on health conditions at birth. They performed an empirical analysis with South American participants. 
(2002) .4 While these studies did not provide a clear theoretical foundation to explain the economic intuition behind their results, we used theory to identify the mechanisms behind such interactions and appreciate how poor health at birth can inhibit skill formation.

Our contribution consists of two related parts to identify various channels that can explain the effect of health at birth on child development and to examine if and how health endowment and parental socioeconomic conditions interact to form child human capital.

We first developed a simple theoretical model based on parental investment in children, in line with the models of human capital formation proposed by Cunha et al. (2010). More specifically, based on an economic approach, we considered the crucial role of parental engagement with the child. Parents being rational and aware that they can affect their children's development, invest a part of their time and financial resources. Returns on this investment depend on parental socioeconomic status and the health status of their children. In this way, the child's endowment affects the behavioural responses of parents. Thus, considering optimising parents' behaviours in the form of time spent with children, health at birth affects human capital through two channels. On the one hand, health at birth can affect children's development directly through a purely biological effect that increases the risk of learning disabilities, academic difficulties, or behavioural problems. On the other hand, parents' engagement in children's development depends on their birth endowment. This indirect effect of health at birth on child human capital can be positive or negative, depending on how child human capital is formed. We assumed a general formalisation in the theoretical part to discuss the different possible cases and to identify the global effect of child's birth endowment. We predicted that health conditions at birth would improve early child development and that parental behaviours can mitigate or amplify this relationship. Concerning the influence of a family's environment on the adverse effect of bad health endowments at birth, we concluded that affluent families suffer less when birth endowments and family's wealth (in the form of income and education) are substitutes to form early childhood human capital.

We then conducted an empirical analysis to test our prediction for France, using a unique dataset on the ELFE cohort's entire French territory. We aimed at empirically analysing the consequences of gestational age and birth weight on child development measured at one

\footnotetext{
${ }^{4}$ Not that it is difficult to give an indisputable explanation for the differences observed across countries as outcomes, explanatory variables, and the periods analysed differ in each study. Nevertheless, their results may suggest less equitable access to child health care in the US.
} 
year. Moreover, we aimed to shed light on differential impacts according to the income and education of the mother. There are several empirical challenges in estimating health's causal effect at birth on child development outcomes. In particular, some omitted variables may be influencing both exposure and outcome. In our analysis, health at birth may be correlated with other factors, such as wealth, which may also be correlated with child development, generating a potential omitted variable bias problem (Shiko and Eskil, 2019). Therefore, if wealthier families are sorting themselves into residential locations with good health conditions, a naive ordinary least squares (OLS) analysis may overestimate health's actual effect.

To mitigate such issues and to infer the impact of health at birth on child development, we first used a rich set of socio-demographic control variables available in the ELFE database. Then, in line with the literature that reports seasonality in the birth outcome, we used the season of birth as an instrumental approach. The intuition to use season of birth as an instrument relies on the fact that it induces seasonal differences in maternal exposure to viral infections, meteorological factors, air pollution, food supply, physical activities, or diet, that directly affects health at birth, independently of parental characteristics (see e.g. Strand et al., 2011, for a recent review of the epidemiological evidence on seasonality of birth outcomes). In this vein, Currie and Schwandt (2013) underlined that higher influenza prevalence in January and February explains an increase in prematurity of more than $10 \%$ during these months $5^{5}$

We first examined the relationship between health at birth and child development. To dissociate the parental investment effect from the biological impact identified in the theoretical part, we then questioned whether parental time investment is related to health at birth. From our results, we identified an effect of gestational age on early child development, mainly due to biological effect. Indeed, our results suggest that parental behaviour does not depend significantly on a child's health at birth. Birth weight is not a relevant determinant of child development in our study, in line with the analysis of Conti et al. (2020), which underlines that birth weight is not informative as it can capture negative and positive aspects of foetal health.

We cannot conclude that there are inequalities in the impact of health at birth on

\footnotetext{
${ }^{5}$ As the authors conducted their analysis using siblings conceived by the same mother at different times, differences in maternal characteristics as an explanation for seasonal differences in health at birth were excluded.
} 
child development, as we found no significant difference depending on the parents' revenue or education profiles of the mother. From our results, there is no evidence that lower family income exacerbates the incidence poor health conditions. Based on our theoretical prediction, this result means that health at birth and parental inputs are not complementary nor substitute to form early childhood human capital.

The rest of the paper is organised as follows. Section 2 presents a simple theoretical model of human capital formation. Section 5 is devoted to presenting the data and the empirical strategy. The results are discussed in Section 5. Section 6 is the Conclusion.

\section{Theoretical framework}

This section develops a theoretical model to highlight the link between birth endowment and human capital.

\section{$2.1 \quad$ Setting}

The concept of human capital refers to individuals' knowledge, skills, and health in different age groups. Thus, it can be cognitive and non-cognitive child development at each age. Our study focusses on cognitive development at age 1 to define the output, and on health at birth (birth weight and gestational age) to define childbirth endowment.

Our first objective in this section is to identify economic mechanisms explaining how and why children's health status, which defines their birth endowment, affects early child outcomes. We paid particular attention to the child's socioeconomic environment in examining this relationship. The idea that health at birth and interventions can affect future health and human capital are well established. However, as recently underlined by Bharadwaj et al. (2018), parents' role in understanding the interplay between a child's endowment and human capital formation is crucial and not well studied. ${ }^{6}$ We provide a benchmark to describe the process of human capital formation during the early life by considering parental investment. Following recent literature that underlines the importance of investment in time during early childhood (see Francesconi and Heckman, 2016, for a review of the literature on child development and parental investment), we considered parental time input in line

\footnotetext{
${ }^{6}$ The role of parents in this interplay is varied. For example, as revealed by O'Neill et al. (2013), early public interventions aimed at supporting parents to address the child's behavioural problems may favour economic returns in the long term.
} 
with Becker $(1965) \cdot !^{7}$

Our study population is composed of households that consist of adults and their children. There are two types of parents $i=l, h$, differentiated by their skills or wealth $W_{i}$, which is the wage that they can obtain in the labour market.

Only parents make decisions. They possess one unit of time which can be partially $e_{i}$ invested to take care of their child (families pre-school-age investments) while the remaining of time is allocated to work and earn the wage $W_{i}$. Parents use their income to consume $c_{i}$ such that their budget constraint is given by:

$$
W_{i}\left(1-e_{i}\right)=c_{i}
$$

Children are characterised by their health endowment at birth $H_{i}$, and we do not consider the effect of parental characteristics on this endowment. Our objective is not to examine socioeconomic inequalities in health at birth and their consequences but rather to identify how parental wealth can affect the sensitivity of human capital formation to a given birth endowment.

Human capital formation refers to how a child's human capital is produced. In theory, child human capital formation occurs mainly in two distinct stages: during early childhood and the schooling process. In utero experience also affects the formation of human capital, but, as previously mentioned, in this study we did not examine health inequality at birth. The formalisation proposed in the literature assumes that human capital at each stage is a function of parental investments, initial endowments, the stock of skills of the previous stage, and parental characteristics (see, e.g. Cunha et al., 2010). For the sake of simplicity, we adapted this formalisation, and assumed a one-period model of childhood. This means that input at any of the stages of childhood are perfect substitutes.8

In our model, human capital is developed by formal investment made by parents. Formal investment refers to parents' level of wealth, the transmission of cognitive and social knowledge within the family, and by child endowment in health. The literature provides evidence that health at birth affects human capital, by its effects on education performance

\footnotetext{
${ }^{7}$ Our general theoretical predictions hold if we assumed that parents directly invest an amount of wealth rather than a unit of time.

${ }^{8}$ Having a one-period model of childhood, we did not distinguish between early investment and late investment, and hence we did not consider dynamic complementarity. This is relevant as our focus is not on the life-cycle profile of investment.
} 
(Figlio et al., 2014; Bharadwaj et al., 2018) or on children's mental health (Currie, 2020). Early childhood human capital is assumed to depend positively on three inputs: health endowment at birth $H_{i}$, a composite of the investment in time made by parents towards child care $e_{i}$, and parent's level of wealth $W_{i}$. We followed Cunha and Heckman (2007) assuming a CES development technology to combine these inputs. Child development is thus governed by:

$$
C D_{i}=\left(\lambda_{1} e_{i}^{\frac{\sigma-1}{\sigma}}+\lambda_{2} H_{i}^{\frac{\sigma-1}{\sigma}}+\lambda_{3} W_{i}^{\frac{\sigma-1}{\sigma}}\right)^{\frac{\sigma}{\sigma-1}} \quad ; \quad \sigma>0
$$

with $\sigma$ capturing the degree of substitutability between the inputs. For $\sigma<1$ health endowment and investment are complements while for $\sigma>1$ they are substitutes.

From Equation 1, we see the importance of health endowment at birth in the formation of human capital. Indeed, identifying health condition as an input of early child development, implies that a better health condition increases the return to childhood investment, i.e. $\frac{\partial^{2} C D_{i}}{\partial e_{i} \partial H_{i}}>0$.

Parents $i$ derive utility from their consumption $c_{i}$ and from their child's development $C D_{i}$. We assumed a Cobb-Douglas utility function such that the parents' choice consists in maximising the following program:

$$
\begin{array}{ll} 
& \max _{c_{i}, e_{i}} \ln c_{i}+\gamma \ln C D_{i} ; 0<\gamma<1 \\
\text { s.t } & W_{i}\left(1-e_{i}\right)=c_{i} . \\
& C D_{i}=\left(\lambda_{1} e_{i}^{\frac{\sigma-1}{\sigma}}+\lambda_{2} H_{i}^{\frac{\sigma-1}{\sigma}}+\lambda_{3} W_{i}^{\frac{\sigma-1}{\sigma}}\right)^{\frac{\sigma}{\sigma-1}}
\end{array}
$$

Our objective is to determine how health at birth affects child development at the equilibrium, meaning when we consider behavioural responses of parents.

\subsection{Interaction between child's health endowment and human capital}

From program 2 , the optimal investment $e_{i}$ satisfies the following equality:

$$
\lambda_{1} e_{i}+\left(\lambda_{2} H_{i}^{\frac{\sigma-1}{\sigma}}+\lambda_{3} W_{i}^{\frac{\sigma-1}{\sigma}}\right) e_{i}^{1 / \sigma}=\lambda_{1} \gamma\left(1-e_{i}\right) \quad \Rightarrow \quad e_{i} \equiv e\left(H_{i}, W_{i}\right)
$$


The overall amount of parental resources spent on children stems from altruistic motives, captured by $\gamma$, and depends on parental income $W_{i}$ if it is complementary or a substitute for other inputs $(\sigma \neq 1)$. Otherwise $(\sigma=1)$, parental income does not affect parental investment. A higher level of wealth generates an income effect, that favours investment in children, and a substitution effect, that makes other investments more profitable. Both effects exactly compensate in our setting when $\sigma=1$ because of the Cobb Douglas utility function.

Using Equations 1 and 3, we got the equilibrium value for the child human capital.

Proposition 1 We got $C D_{i} \equiv C D\left(W_{i}, H_{i}\right)$.

1. Our model predicts that health at birth affects child development through a direct positive effect $\left(\frac{\partial C D_{i}}{\partial H_{i}}\right)$ and through an indirect effect $\left(\frac{\partial C D_{i}}{\partial e_{i}} \times \frac{\partial e_{i}}{\partial H_{i}}\right)$, which is negative (resp. positive) when inputs are substitutes (resp. complements).

2. The global effect of health at birth is positive.

$$
\frac{d C D_{i}}{d H_{i}}=\underbrace{\frac{\partial C D_{i}}{\partial H_{i}}}_{\text {direct effect }}+\underbrace{\frac{\partial C D_{i}}{\partial e_{i}} \times \frac{\partial e_{i}}{\partial H_{i}}}_{\text {indirect effect }}>0
$$

3. The return of a better health status at birth on child development depends on family's characteristics when $\lambda_{3}>0$ and $\sigma \neq 1$. More precisely, child development is less (resp. more) sensitive to health at birth for rich families when inputs are substitutes (resp. complements).

$$
\frac{\partial \varepsilon_{C D_{i} / H_{i}}}{\partial W_{i}} \neq 0
$$

with $\varepsilon_{C D_{i} / H_{i}}$, the elasticity of child development to health at birth:

$$
\varepsilon_{C D_{i} / H_{i}}=\frac{\lambda_{2} H_{i}^{\frac{\sigma-1}{\sigma}}+\lambda_{1} e_{i}^{\frac{-1}{\sigma}} \frac{\partial e_{i}}{\partial H_{i}} H_{i}}{\lambda_{1} e_{i}^{\frac{\sigma-1}{\sigma}}+\lambda_{2} H_{i}^{\frac{\sigma-1}{\sigma}}+\lambda_{3} W_{i}^{\frac{\sigma-1}{\sigma}}}
$$

Our simple model shows that health at birth affects the child through two channels. A direct positive effect that can be viewed as purely biological and an indirect, positive or negative, that goes through parental investment. Investment can increase or decrease with $H_{i}$ depending on how the variables that form human capital interact with each other. To 
evaluate the global effect of health at birth on child development we decomposed the two effects in Equation (4). From (1), we got:

$$
\frac{\partial C D_{i}}{\partial H_{i}}=\lambda_{2} H_{i}^{\frac{-1}{\sigma}}\left(\lambda_{1} e_{i}^{\frac{\sigma-1}{\sigma}}+\lambda_{2} H_{i}^{\frac{\sigma-1}{\sigma}}+\lambda_{3} W_{i}^{\frac{\sigma-1}{\sigma}}\right)^{\frac{1}{\sigma-1}}
$$

Using (1) and (3), we got:

$$
\frac{\partial e_{i}}{\partial H_{i}}=\frac{e_{i}^{\frac{1}{\sigma}}\left(\frac{1-\sigma}{\sigma}\right) \lambda_{2} H_{i}^{\frac{-1}{\sigma}}}{\frac{1}{\sigma}\left(\lambda_{2} H_{i}^{\frac{\sigma-1}{\sigma}}+\lambda_{3} W_{i}^{\frac{\sigma-1}{\sigma}}\right) e_{i}^{(1-\sigma) / \sigma}+\lambda_{1}(1+\gamma)} \times \lambda_{1} e_{i}^{\frac{-1}{\sigma}}\left(\lambda_{1} e_{i}^{\frac{\sigma-1}{\sigma}}+\lambda_{2} H_{i}^{\frac{\sigma-1}{\sigma}}+\lambda_{3} W_{i}^{\frac{\sigma-1}{\sigma}}\right)^{\frac{1}{\sigma-1}}
$$

By combining these two expressions, the global effect is driven by the sign of:

$$
1+\frac{1-\sigma}{\sigma} \frac{\lambda_{1}}{\frac{1}{\sigma}\left(\lambda_{2} H_{i}^{\frac{\sigma-1}{\sigma}}+\lambda_{3} W_{i}^{\frac{\sigma-1}{\sigma}}\right) e_{i}^{(1-\sigma) / \sigma}+\lambda_{1}(1+\gamma)}
$$

which is always positive, meaning that the indirect effect does not undertake the direct one.

Another approach is to ask whether the effects of health endowment are heterogeneous. We aimed to determine if the return of better health status on child development is higher for children with a good socioeconomic environment (i.e., a higher $W_{i}$ ). To achieve this goal, we examined how child development's elasticity to health endowment $\varepsilon_{C D_{i} / H_{i}}$ changes with $W_{i}$. As presented in Proposition 1, this elasticity can differ among households when $\lambda_{3}>0$ and $\sigma \neq 0$. When these two conditions are satisfied, parental characteristics $W_{i}$ affect elasticity directly and indirectly by modifying the way health endowment affects parents' investment $\left(\frac{\partial^{2} e_{i}}{\partial H_{i} \partial W_{i}}\right)$. Both effects depend on input characteristics. When they are complementary $(\sigma>1)$, rich families suffer more from adverse birth outcomes $\left(\frac{\partial \varepsilon_{C D_{i} / H_{i}}}{\partial W_{i}}<0\right)$ while poor families suffer more when inputs are substitutes $\left(\sigma<1 \frac{\partial \varepsilon_{C D_{i} / H_{i}}}{\partial W_{i}}>0\right)$. Parental wealth is not a direct argument for the child development formation $\left(\lambda_{3}=0\right)$, or where inputs are not substitutes or complements $(\sigma=1)$, there is no inequality. The return of better health at birth on child development does not differ among socioeconomic profiles.

Our theoretical results serve to motivate and interpret the observational work that is discussed below. Our aim is not to estimate the theoretical parameters of the human capital function nor to provide an estimated value for human capital. Rather, we examined if our theoretical predictions align with what we observed and concluded using the data. We 
would finally be allowed to deduce some properties regarding how inputs variables interact to form human capital.

\section{$3 \quad$ Data and Empirical Strategy}

\subsection{Data and summary statistics}

Health and child human capital outcomes are drawn from a unique and detailed dataset ELFE - compiled by epidemiologists for the whole of France. ELFE is the first national birth cohort study in France. The ELFE project is a 20-year study of a cohort of 18,300 children recruited in 2011. The purpose is to gain a better understanding of how perinatal conditions and the various aspects of the environment affect children's development, health, and socialisation from the foetal stage to adolescence (see Charles et al., 2019, for details about the cohort profile of ELFE). The data we used in the study included more than 13,000 children from the ELFE cohort interviewed in four waves in 22 regions 9 The wave represents babies born during four specific periods representing each of the four seasons in 2011: 1-4 April, 27 June-4 July, 27 September-4 October, and 28 November-5 December.

We used key variables of the ELFE dataset in our analysis. They covered the data at children's birth in 2011 and one year after birth in 2012. Table 1 presents the summary statistics of these variables.

To define health status at birth, we focussed on birth weight and gestational age. Figure 1 shows the distribution of birth weight as well as the distribution of gestational age.

\footnotetext{
${ }^{9}$ There are several reasons why we do not have 18,300 children in this database. All families whose mothers had given their consent for their children's follow-up in the maternity wards were eligible for the one-year survey. However, not all mothers responded to the one-year survey which led to a loss of many observations. There are some missing observations as well. For example, the Child Development Inventory Index (CD) contains fewer than 14,000 observations because we did not consider the absence of answers to the questions asked. However, the Pearson correlation coefficient between revenue and non-responses to the CD questions is very low, suggesting that non-responses do not bias our estimates.
} 
Figure 1: Gestational age and birth weight distribution
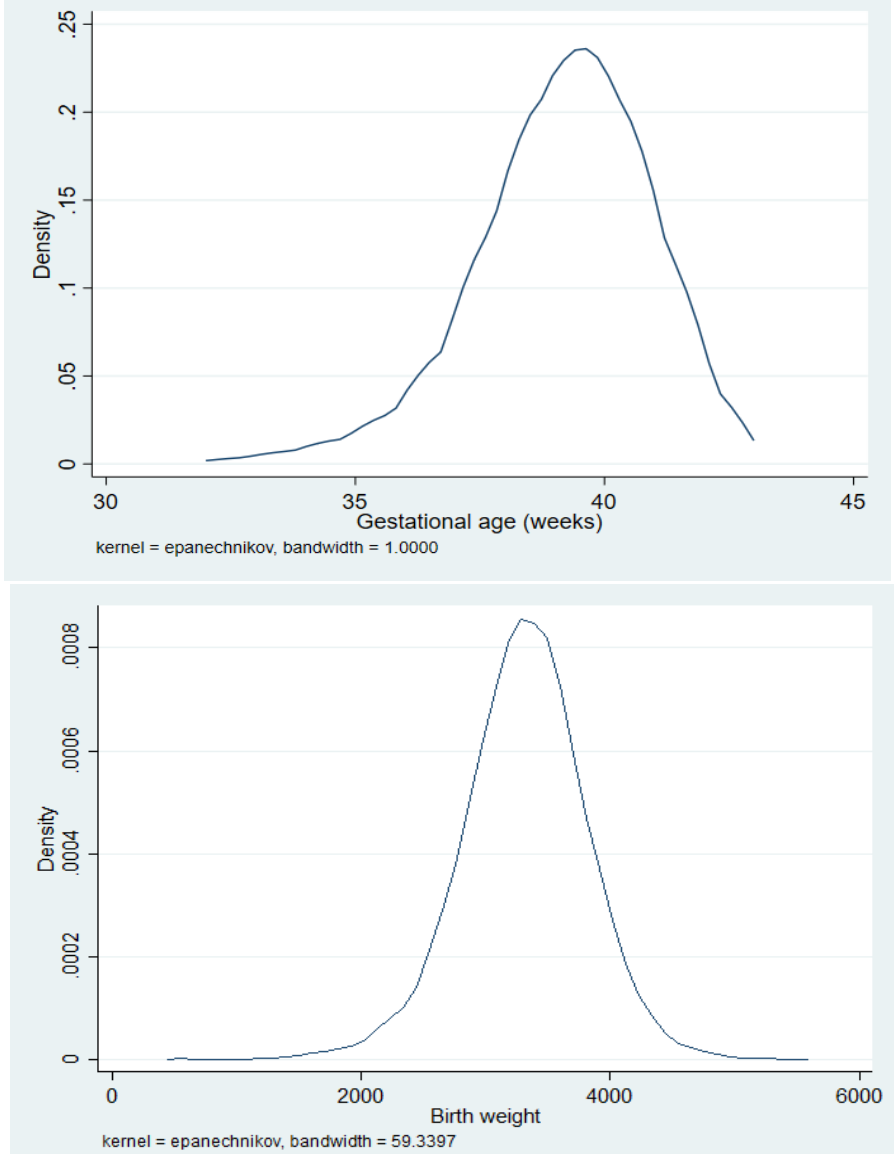

Note: This figure shows the distribution of birth weight and gestational age using Kernel density estimate.

The distribution of birth weight and the distribution of gestational age are approximately normal which justifies our empirical estimation in the next section.

The ELFE cohort allows us to define a relevant measure for capturing early childhood development when the child is one year of age. The cohort provides several variables related to the cognitive performance of the children. They derive from several questions that come from the French version of the "Child Development Inventory" developed by Duyme and Capron (2010) and based on the methodology provided by Ireton (1992). After extensive research over twenty years, Ireton (1992) developed a standardised parent questionnaire to assess the development of infants in their first eighteen months. As reported by Glascoe and Dworkin (1995), parent report measures, such as the "Child Development Inventory," successfully identified children with developmental and behavioural problems. We thus defined a general Child Development Inventory Index (CD) and also a six scale index that mea- 
sures areas of development and learning. They include Social, Self Help, Gross Motor, Fine Motor, Expressive Language, and Language Comprehension scales. T hese indexes can be accepted as a measure of health at one year. A large body of literature has identified health (measured at a particular age in childhood or at birth) as a form of human capital. The literature review provided by Becker (2007) highlights the insights behind this relationship.

In child development questions reported in the ELFE cohort, respondents answered with "yes" or "no" to each question 10 To construct a proxy for child development, we developed an index that corresponds to the percentage of positive responses to questions. The list of questions used to build the CD and the six scales are provided in Appendix 6.1 11

Figure 2 shows the distribution of CD. Unsurprisingly, most of the respondents respond positively to the questions.

Figure 2: CD distribution

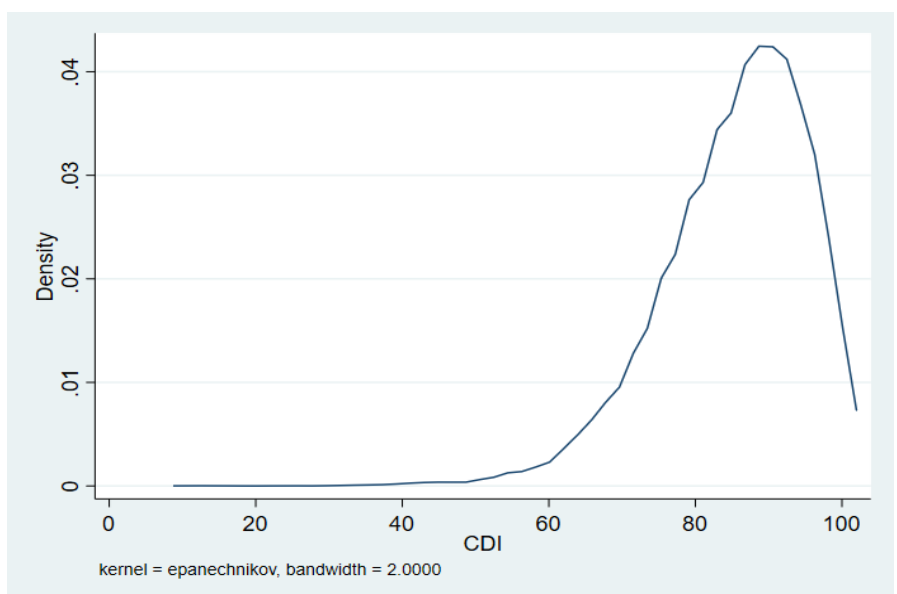

Note: this figure shows the distribution of CD using Kernel density estimate. A detailed description of CD can be found in the Appendix Table 6.1.

The literature argues that the time parents spend with their children plays a critical role in health (Rowe et al., 2016). Parent-child time can be seen as a form of human capital investment that plays a vital role during early life. The link between parental time and early childhood development is poorly documented in the empirical literature Wehby et al. (2012). Parental time investments in children have been considered as an input in child

\footnotetext{
${ }^{10}$ We did not consider the ones who do not respond to the questions. They are considered as "." in the analysis.

${ }^{11}$ Note that these questions are included in the ELFE survey; we were not in a position to design them. They correspond to the methodology used by Ireton (1992) and their validity is well established.
} 
outcomes Del Boca et al. (2014). Del Bono et al. (2016) and more recently Bharadwaj et al. (2018) made significant contributions in this regard. Still, they did not evaluate the effects of parental investments in very early life stages. In this vein, we constructed an index that considers the time parents spend with their own children. To do so, we used several ELFE variables. The one-year interview includes several questions about activities parents do with their children (small games, reading, drawing, watching television, talking, singing, physical games, and others). These categorical variables provide information about the time mothers spent on particular activities ${ }^{12}$ We constructed a variable counting the percentage of answers in which the mother performs the activity frequently, and use it as another dependent variable in the estimation. In this way, we could examine the different components that defined the effect of health on child development presented in the theoretical model (see Equation 4. We could confirm that parental investment was input to child development in the theoretical model. Nevertheless, it was also an endogenous variable and, more precisely, an output of the parents' optimisation program. Hence, considering parental choices, we obtained an equilibrium value for the parental investment that depended on several variables and, in particular on children's' health at birth. For this reason, parental investment was considered as a dependent variable of interest.

We used several control variables recognised as determinants of health and cognitive development in the literature (Ouidir et al., 2017). For the family environment, we used the age of the mother, average monthly income per household member in Euro, French as the home language for the mother and the father, type of housing, ${ }^{13}$ its location in the geographic area namely rural or urban; if the mother has moved during pregnancy and if the child is looked after by someone else than the mother. We also controlled for mother's education, as it is identified as an important determinant of the health of children (Chen and Li, 2009) ${ }^{14}$ Considering the result of Panico et al. (2019) which indicated that family status correlates to children's early physical health, we also controlled for this dimension by distinguishing between being married, cohabitation, civil union, and single parenting. We also included behavioural variables to capture the behaviour of the mother during pregnancy:

\footnotetext{
${ }^{12}$ It would be interesting to examine differences between maternal and paternal involvement. Nonetheless, this question cannot be addressed in our study as data for father is not well documented. We thus considered only maternal investment to construct our variable.

${ }^{13}$ Mothers could choose between three items to define housing type: 1 - an individual house; 2 - an apartment; and 3 - other types

${ }^{14}$ For mother education, we have: 1 "below high school" 2 "high school" 3 "bachelor" 4 "master." They represent $8 \% ; 33 \% ; 22 \%$ and $36 \%$ of the sample respectively.
} 
time spent in cleaning, to do prenatal exercise, or to work at home ${ }^{15}$ We considered the mother's perception of a child's health when the child was two months and one year old 16 We also controlled if children had a recognised health issue. ${ }^{17}$ We controlled for the number of siblings when the child was one year, for twin birth and the sex of the child. We also added some technical control variables specific to the ELFE cohort, namely the child's ranking in the ELFE cohort 18 Cohort ranking gives the birth order among siblings (1 indicates that the child is the firstborn). The ELFE survey was conducted on a random sample of maternity hospitals in France and comprised 349 of the 544 facilities surveyed. This choice was due to the distribution of maternity hospitals in terms of their size, level of medicalization, geographical location, and legal status. The fact that maternity hospitals have an unequal probability of being selected according to their size will lead to a different weight being assigned to them, in order to adjust the sample for statistical analysis. This weight is used in the analysis. Most of the data collection was based on regular surveys of parents. Data were collected at birth through interviews with the mothers in the maternity wards. At the ages of two months and one year, phone surveys were done with the children's parents. 19

\footnotetext{
${ }^{15}$ For time spent in cleaning and to do prenatal exercise, mothers were asked to indicate on a six-point scale how frequently they performed the activity per week, ranging from 1 "never" to 6 "more than three hours per week."

${ }^{16}$ Respondent indicates whether the health of his child is: 1 "good," 2 "somewhat good," 3 "somewhat bad," 4 "'bad"

${ }^{17} 1$ "yes" 0 "no"

${ }^{18} 1$ means that the child is the firstborn

${ }^{19}$ TIME INVESTMENT, CD and HEALTH PERCEPTION were determined at one year of age. Other information was gathered at the maternity hospital. HEALTH PERCEPTION was also determined at two months.
} 
Table 1: Summary Statistics

\begin{tabular}{|c|c|c|c|}
\hline Variables & Description & mean & sd \\
\hline & \multicolumn{3}{|l|}{ A. Dependent variables } \\
\hline $\mathrm{CD}$ & Child development inventory index (\%) & 85.32 & 9.85 \\
\hline \multirow[t]{2}{*}{ TIME INVESTMENT } & Time spent with child (\%) & 57.52 & 18.40 \\
\hline & \multicolumn{3}{|l|}{ B. Independent variables } \\
\hline GEST. AGE & Gestational age (weeks) & 39.16 & 1.50 \\
\hline \multirow[t]{2}{*}{ BIRTH WEIGHT } & Birth weight (grams) & 3309.47 & 499.38 \\
\hline & \multicolumn{3}{|l|}{ C. Control variables } \\
\hline REVENUE & Average monthly income per household member (Eur) & 1631.33 & 1008.69 \\
\hline MEDUC & Level of mother's education & 2.87 & 1.00 \\
\hline 1 & below high school & .07 & .27 \\
\hline 2 & high school & .33 & .47 \\
\hline 3 & bachelor & .21 & .41 \\
\hline 4 & master & .36 & .48 \\
\hline MAGE & Mother's age & 30.80 & 5.06 \\
\hline FAMILY STATUS & Family status & 2.39 & 1.22 \\
\hline 1 & Married with the father of the child & 0.37 & 0.48 \\
\hline 2 & Civil union with the father of the child & 0.11 & 0.32 \\
\hline 3 & Cohabiting in couple with the father of the child & 0.25 & 0.43 \\
\hline 4 & other & 0.25 & 0.43 \\
\hline CHILDCARE & $\begin{array}{l}\text { The child is look after by someone else } \\
\text { than the mother (=1 if yes) }\end{array}$ & 0.13 & 0.33 \\
\hline RELOCATION & Move during pregnancy (=1 if yes) & 0.13 & 0.33 \\
\hline HOUSE TYPE & Type of housing & 1.62 & 0.69 \\
\hline 1 & House & 0.5 & 0.5 \\
\hline 2 & Flat & 0.38 & 0.48 \\
\hline 3 & Others & 0.11 & 0.32 \\
\hline URBAN & Urban area of living ( $=1$ if yes) & 0.56 & 0.50 \\
\hline EXERCISE & Prenatal exercise & 0.27 & 0.77 \\
\hline CLEAN TIME & Time spent to clean up & 2.56 & 1.48 \\
\hline HOME WORKING & Work at home during pregnancy (=1 if yes) & 0.04 & 0.19 \\
\hline MLENGHOME & Mother speaks french at home ( $=1$ if yes $)$ & 0.94 & 0.23 \\
\hline FLENGHOME & Father speaks french at home $(=1$ if yes $)$ & 0.97 & 0.18 \\
\hline HEALTH PERCEPT. 2M & Mother's perception of child health at two months & 1.14 & .39 \\
\hline HEALTH PERCEPT. $1 Y$ & Mother's perception of child health at one year & 1.20 & 0.44 \\
\hline HEALTH ISSUE & Recognized health issues ( $=1$ if yes) & 0.01 & 0.12 \\
\hline SIBLINGS & Number of siblings & 0.83 & 0.93 \\
\hline SEX & Gender ( $=2$ if male) & 1.49 & 0.50 \\
\hline TWINS & Twins $(=1$ if yes $)$ & 0.03 & 0.17 \\
\hline COHORT RANKING & Child births' order in the ELFE cohort & 1.83 & 1.01 \\
\hline COHORT WEIGHT & Cohort ELFE weight (\%) & 67.98 & 60.50 \\
\hline & D. Instrumental variable & & \\
\hline SEASON OF BIRTH & ELFE Waves & 2.75 & 1.05 \\
\hline
\end{tabular}

Note: The time period covered in the analysis is 2011 and 2012 , and the unit of analysis is the child - wave - region. There are 13235 observations in the studied sample. A detailed description of child development can be found in the Appendix Table 6.1 


\subsection{Empirical strategy}

We analysed the impact of health at birth on child development. As a baseline, we first estimated the following empirical model.

$$
Y_{i r}=\alpha_{0}+\beta_{1} H_{i r}+\mu X_{i r}+\alpha_{r}+\xi_{i r}
$$

where $Y_{i r}$ represents $\mathrm{CD}$ or parental time investment for child $i$ living in a region $r 20$ Coefficient $\beta_{1}$ measures the direct marginal effect of a child health status on $Y_{i r} . H_{i r}$ is a health at birth variable that includes birth weight and gestational age. $X_{i r}$ is a vector of child controls as described in the previous section and in Panel $\mathrm{C}$ of Table 1 . We also added regional fixed effects. More particularly, $\alpha_{r}$ controls for time invariant specific regional characteristics. $\xi_{i r}$ represents the error term.

When estimating Equation 6 using the longitudinal dataset at the child level, we controlled for several family characteristics that can affect health at birth and child development. Despite this effort, our results could still be affected by endogeneity issues. While reverse causality is excluded in our analysis (the birth outcome is measured before child's development), it may exist in several unobserved factors that could influence both health and child development. We needed to construct a measure of health endowment to overcome these common endogeneity issues. Our identification strategy used an instrumental variable approach (IV). Hence, the primary estimation relies on an IV specification to obtain an exact identification of the effect of health on child development.

To instrument child health endowment at birth, we used the ELFE interview wave corresponding to the season of advent. More precisely, the ELFE cohort represents babies born during four specific periods representing each of the four seasons in 2011: 1-4 April, 27 June - 4 July, 27 September - 4 October, and 28 November - 5 December. As with any IV design, the critical underlying assumption for identification is that the instrument is valid. A helpful device satisfies two conditions. In our context, (i) it has to be a good predictor of birth outcomes, and (ii) birth outcomes should be the only factor explaining the impact of seasonality of birth on child development. The first condition seems to be met. A large body of literature confirms the impact of seasonality on foetal health. Strand et al. (2011) provided a review of the evidence on seasonality of birth outcomes, paying particular

\footnotetext{
${ }^{20}$ The unit of observation is the child.
} 
attention to seasonal environmental and meteorological factors. They identified 20 studies that reported statistically significant seasonal patterns in birth outcomes. In addition to environmental and meteorological factors, many other mechanisms have been explored to understand seasonality in birth outcomes. They include seasonal variation in viral infections, allergies, eating patterns, or physical activities. Recently, Currie and Schwandt (2013) identified higher influenza prevalence in months of birth as a factor of prematurity with winter being preponderant for viral infections. Our dataset supported this evidence as winter corresponded to wave 4 . The first stage estimation in Table 3 showed that our instrumental variable had a significant and negative effect on birth outcomes $\left(-0.0326^{* *}\right)$. The first condition was therefore satisfied.

For the exclusion restriction assumption (ii) to be valid, the birth season had to be uncorrelated with early child development and other relevant explanatory variables. There have been extensive discussions in the literature to determine if the associations between birth outcome and season of birth are driven by socioeconomic conditions around the period of conception. As emphasised by the study of Buckles and Hungerman (2013), no clear consensus emerged. While these authors provided evidence relating to season of birth and maternal characteristics in the US, the study by Currie and Schwandt (2013) concluded that, even if selection exists, the bias it entails is relatively small. The authors find seasonal patterns in birth weight and gestation that were not driven by the fact that heterogeneous women tended to give birth in different seasons. There is no evidence of such a relationship between family background characteristics and seasonality in France. Exploring the correlation between the four cohort waves - a proxy for season of birth - and household income, mothers' education, or marital status showed no seasonal pattern in our data. The associated box plot in Figure 3 showed very few differences between the four birth waves for household income, mother's education, or marital status. The finding suggested that the season of birth influenced early child development mainly through the birth outcomes channel and hence satisfied relevant exclusion restrictions. 21

\footnotetext{
${ }^{21}$ Several studies have highlighted the fact that season of birth affects long-term child development because of its effect on the age of pre-school entry. As we focussed on early child development at one year, this channel is not relevant for our study.
} 
Figure 3: Season of birth and socioeconomic characteristics

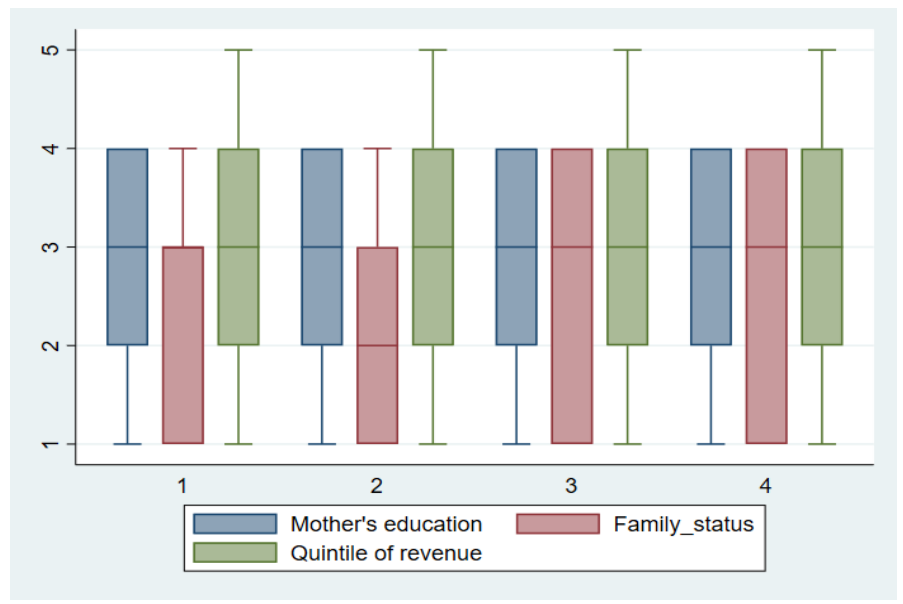

Note: this figure represents box plots of mother's education, household's revenue and family status over season of birth. The $\mathrm{X}$ axis represents the 4 cohort waves.

We then estimate the following IV model:

$$
\begin{gathered}
H_{i r}=\alpha_{1}+\beta_{2} S E A S O N_{-} O F_{-} B I R T H_{i r}+\delta X_{i r}+\omega_{r}+\epsilon_{i r} \\
Y_{i r}=\alpha_{2}+\beta_{3} \hat{H}_{i r}+\mu X_{i r}+\alpha_{r}+\xi_{i r}
\end{gathered}
$$

Where health of child $i$, living in region $r\left(H_{i r}\right)$ in Equation 8 has been instrumented by the season of birth from Equation 7. Coefficient $\beta_{3}$ in Equation 8 represents our coefficient of interest and measures the causal effect of a child's health status on CD. Both equations again rely on regional fixed effects as well as a vector of controls for child characteristics. Nevertheless, we should note that the IV estimator only captures the effects among the compliers, whose health at birth is impacted by the variation of season of birth. We also underline some empirical limitations in the empirical section.

\section{Results}

\subsection{The impact of health on early child development}

We start by examining the effect of health at birth on child development $\left(\frac{d C D_{i}}{d H_{i}}\right.$ in the theoretical model). Figure 4 provides a scatter plot of the relationship between birth weight and 
child development as well as the relationship between gestational age and child development.

Figure 4: the relationship between early child development and birth weight or gestational age
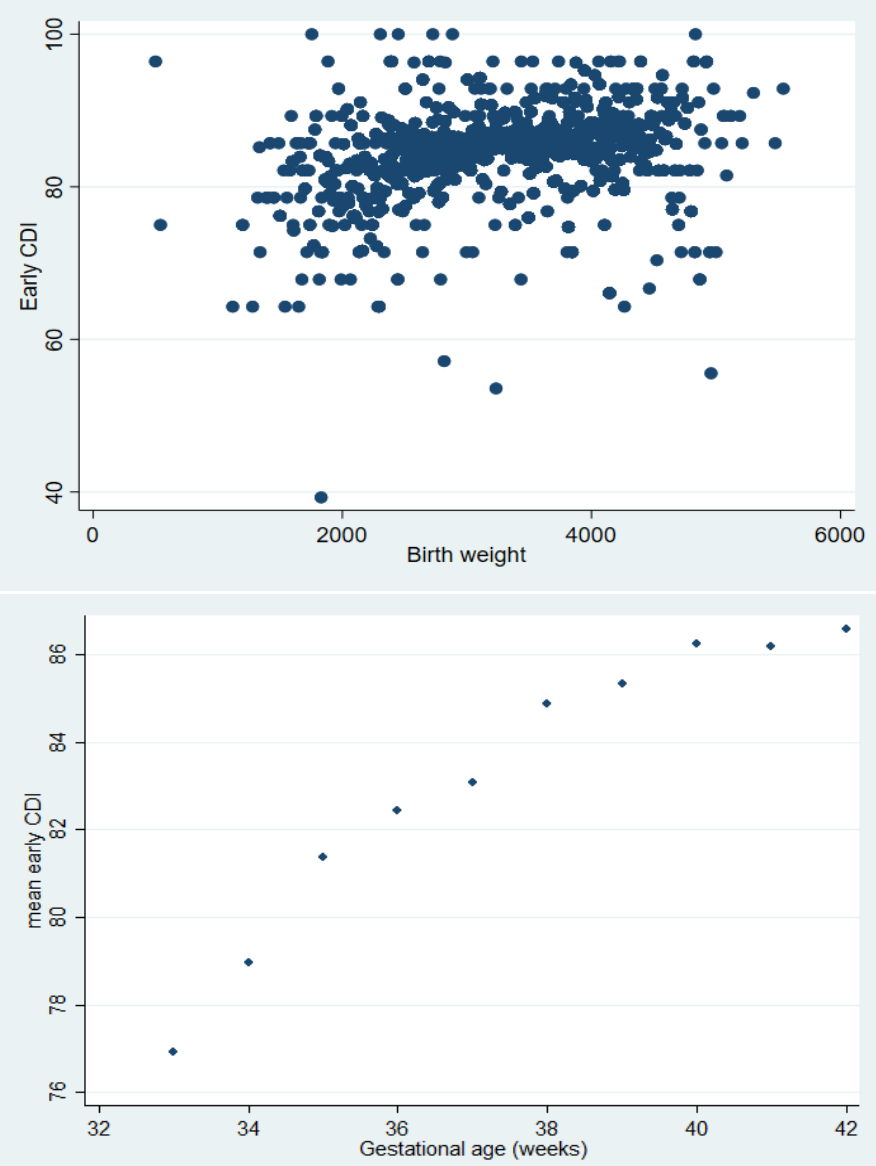

Note: These figures plot the descriptive relationship between child development and birth weight or gestational age. The horizontal axis measures birth weight or gestational age. The vertical axis measures child development. 
There is a direct relationship between gestational age and our index of child development; Child development has a strong positive relationship with gestational age: the higher the gestational age, the higher the index of child development. By contrast, this measure of human capital exhibits no clear association with birth weight.

\subsubsection{OLS analysis}

Table 2 provides regression estimates of Equations 6 (OLS) which are largely analogous to this Figure. In Table 2, we present the results on the full sample using gestational age (Columns 1-2) or birth weight (Columns 3-4) as health indicators. 
Table 2: The impact of health on child development - OLS estimation

Dependent variable: early child development

(3)

\begin{tabular}{|c|c|c|c|c|}
\hline GEST. AGE & $\begin{array}{c}0.812^{* * *} \\
(0.0572)\end{array}$ & $\begin{array}{c}0.597^{* * *} \\
(0.0787)\end{array}$ & & \\
\hline BIRTH WEIGHT & & & $\begin{array}{c}0.00190 * * * \\
(0.000174)\end{array}$ & $\begin{array}{c}0.00163^{* * * *} \\
(0.000238)\end{array}$ \\
\hline REVENUE & $\begin{array}{c}-0.000299^{* * *} \\
(0.0000934)\end{array}$ & $\begin{array}{r}-0.0000658 \\
(0.000142)\end{array}$ & $\begin{array}{c}-0.000302^{* * *} \\
(0.0000940)\end{array}$ & $\begin{array}{r}-0.0000713 \\
(0.000143)\end{array}$ \\
\hline MEDUC & $\begin{array}{c}-0.0914 \\
(0.0949)\end{array}$ & $\begin{array}{l}0.233^{*} \\
(0.140)\end{array}$ & $\begin{array}{l}-0.0647 \\
(0.0956)\end{array}$ & $\begin{array}{l}0.252^{*} \\
(0.141)\end{array}$ \\
\hline MAGE & & $\begin{array}{c}-0.175^{* * * *} \\
(0.0290)\end{array}$ & & $\begin{array}{c}-0.167^{* * * *} \\
(0.0293)\end{array}$ \\
\hline CHILDCARE & & $\begin{array}{c}0.620^{* *} \\
(0.315)\end{array}$ & & $\begin{array}{c}0.683^{* *} \\
(0.318)\end{array}$ \\
\hline RELOCATION & & $\begin{array}{l}0.643^{*} \\
(0.329)\end{array}$ & & $\begin{array}{l}0.606^{*} \\
(0.332)\end{array}$ \\
\hline SIBLINGS & & $\begin{array}{l}0.590^{*} \\
(0.309)\end{array}$ & & $\begin{array}{c}0.478 \\
(0.312)\end{array}$ \\
\hline FAMILY_STATUS & & & & \\
\hline $2--$ & & $\begin{array}{c}-0.638^{* *} \\
(0.300)\end{array}$ & & $\begin{array}{c}-0.564^{*} \\
(0.301)\end{array}$ \\
\hline 3 & & $\begin{array}{c}0.277 \\
(0.263)\end{array}$ & & $\begin{array}{c}0.353 \\
(0.265)\end{array}$ \\
\hline 4 & & $\begin{array}{l}1.065 \\
(0.657)\end{array}$ & & $\begin{array}{l}1.109^{*} \\
(0.662)\end{array}$ \\
\hline TWINS & & $\begin{array}{c}-2.269^{* * * *} \\
(0.710)\end{array}$ & & $\begin{array}{c}-2.500^{* * * *} \\
(0.708)\end{array}$ \\
\hline SEX & & $\begin{array}{c}1.602^{* * *} \\
(0.215)\end{array}$ & & $\begin{array}{c}1.873^{* * *} \\
(0.218)\end{array}$ \\
\hline HOUSE TYPE & & & & \\
\hline 2 & & $\begin{array}{c}0.582^{* *} \\
(0.261)\end{array}$ & & $\begin{array}{c}0.640^{* *} \\
(0.262)\end{array}$ \\
\hline $\mathrm{cos}^{\circ} \mathrm{s}$ & & $\begin{array}{c}0.335 \\
(1.849)\end{array}$ & & $\begin{array}{c}0.230 \\
(1.852)\end{array}$ \\
\hline HEALTH PERCEPTION $1 Y$ & & $\begin{array}{c}-0.987^{* * *} \\
(0.248)\end{array}$ & & $\begin{array}{c}-0.983^{* * * *} \\
(0.249)\end{array}$ \\
\hline HEALTH PERCEPTION 2M & & $\begin{array}{l}-0.387 \\
(0.288)\end{array}$ & & $\begin{array}{l}-0.405 \\
(0.290)\end{array}$ \\
\hline HEALTH ISSUE & & $\begin{array}{c}-1.491^{* *} \\
(0.724)\end{array}$ & & $\begin{array}{c}-1.607^{* *} \\
(0.728)\end{array}$ \\
\hline EXERCICE & & $\begin{array}{c}0.482^{* * * *} \\
(0.129)\end{array}$ & & $\begin{array}{c}0.491 * * * \\
(0.130)\end{array}$ \\
\hline CLEAN TIME & & $\begin{array}{c}0.209 * * * \\
(0.0768)\end{array}$ & & $\begin{array}{c}0.240^{* * *} \\
(0.0772)\end{array}$ \\
\hline HOME WORKING & & $\begin{array}{c}0.706 \\
(0.571)\end{array}$ & & $\begin{array}{c}0.770 \\
(0.580)\end{array}$ \\
\hline MLENGHOME & & $\begin{array}{l}-0.102 \\
(0.763)\end{array}$ & & $\begin{array}{l}0.0367 \\
(0.771)\end{array}$ \\
\hline FLENGHOME & & $\begin{array}{l}-0.476 \\
(0.811)\end{array}$ & & $\begin{array}{l}-0.334 \\
(0.816)\end{array}$ \\
\hline URBAN & & $\begin{array}{l}0.643^{* *} \\
(0.271)\end{array}$ & & $\begin{array}{c}0.685 * * \\
(0.272)\end{array}$ \\
\hline COHORT RANKING & & $\begin{array}{l}-0.502 \\
(0.308)\end{array}$ & & $\begin{array}{c}-0.532^{*} \\
(0.311)\end{array}$ \\
\hline COHORT WEIGHT & & $\begin{array}{c}0.0103^{* * * *} \\
(0.00267)\end{array}$ & & $\begin{array}{c}0.0106^{* * *} \\
(0.00269)\end{array}$ \\
\hline Regional FE & Yes & Yes & Yes & Yes \\
\hline Observations & 13235 & 7711 & 13080 & 7631 \\
\hline $\mathrm{R} 2$ adjusted & 0.0217 & 0.0445 & 0.0159 & 0.0431 \\
\hline F Test & 13.25 & $22^{8.985}$ & 9.796 & 8.629 \\
\hline
\end{tabular}

Note: This table estimates the impact of gestational age and birth weight on cognitive development. The dependent variable is the Early child development. All estimations contain regional fixed effect. Standard errors (in parenthesis)

Statistical significance is denoted by: ${ }^{*} p<0.10,{ }^{* *} p<0.05,{ }^{* * *} p<0.01$ 
Consistent with figure 4. Column 1 shows that the direct impact of gestational age is an increase in child development of $0.8 \%$ on the total sample not controlling for child characteristics. In Column 2, we controlled for additional child characteristics. This slightly decreases the coefficient (0.6\%). Table 2 repeats the exercise in Columns 3 and 4 using birth weight. There is a positive impact of birth weight on child development which is very small. It was in line with the analysis of Conti et al. (2020), underlining that birth weight is not necessarily a relevant proxy of health at birth.

Turning to control variables, our study shows that being a girl has a positive correlation with child development, in line with the literature that revealed the gender gap in educational attainment in favour of women (see Figlio et al., 2019, for a recent contribution). Our results suggest that the gender gap is observed very early. Mothers' age is negatively related to child development. This is in line with the evidence which showed that risk aversion increases with age (Hryshko et al. 2011$)$ while parental risk aversion has a significant negative effect on children's educational attainment (Checchi et al., 2014). Being look after by someone else than the mother is positively related with child development. The coefficient of relocation is significant and positive, which seems to suggest that relocation offers a better quality of life, which would have positive repercussions on children's health at birth (Struening et al., 1990). Living in an urban area is positively related to child's health. Douthit et al. (2015) highlighted the existence of essential barriers to health care access in rural areas. There is also a positive correlation between engaging in prenatal exercises or spending time in cleaning during pregnancy and child development. In contrast, twins' birth as specific child health disabilities at one year is negatively related with child development. Mother's education was positively related to child development in the simple OLS, while the coefficient for household income was not significant in the model with control variables (Columns 2 and 4). A possible explanation is that a household's income can affect child development through several channels (as described in the theoretical model) that can play in opposite direction. For example, the opportunity cost to invest in children differs among heterogeneous households, which can mitigate the assumed positive effect of income/education on child development. 22 The coefficient related to the number of siblings, house type, family status, and birth order are significant and going in the right direction.

Columns 1, 2, 4 and 5 of Table 7 in the Appendix repeats the previous exercise done

\footnotetext{
${ }^{22}$ The study of Del Boca et al. $(2014)$ provides some arguments in this sense.
} 
in Table 2 with different specifications as robustness checks. In the first panel, we remove one twin from the sample over the 268 pairs of the dataset's twins. Twins share the same socioeconomic characteristics which could bias the estimation results. The second panel adds the time parents spend with their child as new control variables. This is in line with the definition of the child development function presented in the theoretical part, which defined time investment as an input to form child development. In the third panel, we follow Conti et al. (2020) 's methodology, controlling for gestational age. Indeed, to identify the effect of health variables at birth (notably foetal growth indices) on children's cognitive development and health capital at different ages, Conti et al. (2020) controlled for gestational age at birth. We finally added wave fixed effect to consider specific impacts due to temporal variation. The four panels support our previous results. Gestational age has a positive effect on child development while birth-weight impact stays very low. The size of coefficients is nearly similar to those in Table.2.

Using the same exercises as those shown in Table 2, we present in the Table 8 of the Appendix the results for the different subcategories of the child development inventory. Gestational age has a positive and highly significant effect on expressive language, comprehensive language, self-help scales, and fine and growth motor scales. The growth motor's coefficient is exceptionally high, in line with the literature (Dewey et al., 2011). The effect on a social scale is not significant. This can be explained by the fact that it is difficult to capture heterogeneity in human capital at one year examining social activities.

\subsubsection{Instrumental analysis}

To examine if the significant effect of gestational age is robust, Table 3 presents the results with the instrumental variable. Results of the IV analysis (Equation 7) are split into two panels. The first one corresponds to the 2SLS estimation, while the second one highlights the first-stage. More precisely, the first-stage of the estimation of the IV analysis emphasises that our instrumental variable has a highly significant effect on gestational age (Column 1). As expected, the result is negative. In line with Currie and Schwandt (2013) that underline that higher influenza prevalence in winter explains an increase in prematurity, our results show a decrease in gestational age going closer to winter. Similar to Currie and Schwandt (2013), the season of birth does not significantly affect birth weight. We also conducted an $\mathrm{F}$ test to ensure that our instrument is relevant. While small, the F-statistic of a joint 
test whether all excluded instruments are significantly different from zero is positive and significant (Table 3).

Columns 3 and 6 of Table 7 in the Appendix repeats the exercise done in the second stage of Table 3 with different specifications as robustness checks. The fourth panel does not show coefficients for IV as season of birth cannot be used as an instrument as well as fixed effects. The birth weight is not significant in the IV estimation, in line with the argument previously presented. As for OLS, the IV analysis emphasizes that a one-week increase in gestational age increases child development. Note that IV estimates are larger than OLS estimates (in line with Broner et al. (2012)). We are cautious with this increase of the coefficient's size, which may be due to measurement error specific to our instrument. We thus prefer to refer to OLS for coefficient interpretation. More precisely, from OLS a one-week increase in gestational age increases child development by roughly $0.6 \%$ from the baseline mean.

Table 3: The impact of health on early child development: 2SLS estimation

\begin{tabular}{|c|c|c|}
\hline $\begin{array}{l}\text { 2nd stage } \\
\text { Dependent variable }\end{array}$ & $\begin{array}{c}\text { early child development } \\
\text { (1) }\end{array}$ & $\begin{array}{c}\text { early child development } \\
(2)\end{array}$ \\
\hline GEST. AGE & $\begin{array}{l}11.62^{*} \\
(6.435)\end{array}$ & \\
\hline BIRTH WEIGHT & & $\begin{array}{r}-0.0923 \\
(0.124)\end{array}$ \\
\hline Control variables & Yes & Yes \\
\hline Regional FE & Yes & Yes \\
\hline Observations & 7711 & 13080 \\
\hline F Test & 2.237 & 0.364 \\
\hline $\begin{array}{l}\text { 1st stage } \\
\text { Dependent variable }\end{array}$ & $\begin{array}{l}\text { GEST. AGE } \\
\text { (1) }\end{array}$ & $\begin{array}{l}\text { BIRTH WEIGHT } \\
(2)\end{array}$ \\
\hline SEASON OF BIRTH & $\begin{array}{c}-0.0311^{* *} \\
(0.0154)\end{array}$ & $\begin{array}{c}3.999 \\
(5.162)\end{array}$ \\
\hline Control variables & Yes & Yes \\
\hline Regional FE & Yes & Yes \\
\hline Observations & 7711 & 7631 \\
\hline R2 Adjusted & 0.0929 & 0.108 \\
\hline F Test & 18.54 & 21.62 \\
\hline F test of excluded instrument & $4.20^{* *}$ & 1.14 \\
\hline
\end{tabular}




\subsection{Parental investment and health at birth}

Then, we examined whether and how parental investment depends on health at birth. No clear evidence exists on this point, and the theory tells that it is important to examine it to understand the relationship between health at birth and a child's development. As shown previously, the theoretical model predicts that health at birth affects the child's development through direct biological effects and through behavioural responses (time investment). The previous Table 2 highlights that the global effect is positive. To disentangle both effects, we treated time investment as an output variable and estimated the impact of health on it in Table 4. Therefore, we repeated the exercise done in Table 2 replacing child development by time investment as a dependent variable. ${ }^{23}$ We found no significant effect of gestational age nor birth weight on time investment in each of our specifications. ${ }^{24}$ This latter result suggests that time investment and health at birth are not complement nor substitute as discussed in the previous theoretical section. Concerning Proposition 1 from the theoretical section, our empirical results show that the sensitivity of early child development to health in France does not depend on parental time investment $\left(\frac{\partial e_{i}}{\partial H_{i}}\right.$ is not significantly different from 0$)$. Thus, we can assess that the significant effect of health at birth on early child development, $\frac{d C D_{i}}{d H_{i}}$, observed in Table 2 , is only related to a purely biological effect, $\frac{\partial C D_{i}}{\partial H_{i}}$.

\footnotetext{
${ }^{23}$ By definition, in the theoretical model, there is a positive relationship between parental time investment and a child's development. This property is widely admitted and formalised in the literature. Our study did not examine this relationship, even if Table 7 in the Appendix provides some intuition about it.

${ }^{24}$ The impact of birth weight is significant in Column 3, but this result does not hold when adding relevant control variables.
} 
Table 4: The impact of health on time investment

\begin{tabular}{|c|c|c|c|c|}
\hline \multirow{2}{*}{ GEST. AGE } & \multicolumn{4}{|c|}{$\begin{array}{l}\text { Dependent variable: parental time investment } \\
\text { OLS estimation }\end{array}$} \\
\hline & $\begin{array}{l}-0.125 \\
(0.109)\end{array}$ & $\begin{array}{l}-0.121 \\
(0.149)\end{array}$ & & \\
\hline BIRTH WEIGHT & & & $\begin{array}{c}-0.00113^{* * *} \\
(0.000329)\end{array}$ & $\begin{array}{r}-0.0000458 \\
(0.000450)\end{array}$ \\
\hline REVENUE & $\begin{array}{l}-0.000236 \\
(0.000177)\end{array}$ & $\begin{array}{l}-0.000338 \\
(0.000269)\end{array}$ & $\begin{array}{l}-0.000249 \\
(0.000178)\end{array}$ & $\begin{array}{l}-0.000348 \\
(0.000270)\end{array}$ \\
\hline MEDUC & $\begin{array}{c}-0.421^{* *} \\
(0.181)\end{array}$ & $\begin{array}{l}0.0616 \\
(0.264)\end{array}$ & $\begin{array}{c}-0.396^{* *} \\
(0.181)\end{array}$ & $\begin{array}{l}0.0779 \\
(0.266)\end{array}$ \\
\hline MAGE & & $\begin{array}{l}-0.0570 \\
(0.0548)\end{array}$ & & $\begin{array}{l}-0.0719 \\
(0.0553)\end{array}$ \\
\hline CHILDCARE & & $\begin{array}{l}-0.437 \\
(0.596)\end{array}$ & & $\begin{array}{l}-0.529 \\
(0.601)\end{array}$ \\
\hline RELOCATION & & $\begin{array}{l}-0.308 \\
(0.621)\end{array}$ & & $\begin{array}{l}-0.363 \\
(0.626)\end{array}$ \\
\hline SIBLINGS & & $\begin{array}{c}-1.471^{* *} \\
(0.584)\end{array}$ & & $\begin{array}{c}-1.394^{* *} \\
(0.589)\end{array}$ \\
\hline FAMILY STATUS & & & & \\
\hline 2 & & $\begin{array}{l}-0.139 \\
(0.567)\end{array}$ & & $\begin{array}{c}-0.0999 \\
(0.569)\end{array}$ \\
\hline 3 & & $\begin{array}{c}1.406^{* * *} \\
(0.498)\end{array}$ & & $\begin{array}{c}1.436^{* * *} \\
(0.501)\end{array}$ \\
\hline 4 & & $\begin{array}{r}0.0157 \\
(1.243)\end{array}$ & & $\begin{array}{c}-0.0599 \\
(1.250)\end{array}$ \\
\hline TWINS & & $\begin{array}{c}-3.355^{* *} \\
(1.343)\end{array}$ & & $\begin{array}{c}-3.029^{* *} \\
(1.338)\end{array}$ \\
\hline SEX & & $\begin{array}{c}1.129^{* * *} \\
(0.405)\end{array}$ & & $\begin{array}{c}1.082^{* * *} \\
(0.412)\end{array}$ \\
\hline HOUSE TYPE & & & & \\
\hline 2 & & $\begin{array}{c}1.424^{* * *} \\
(0.493)\end{array}$ & & $\begin{array}{c}1.398^{* * *} \\
(0.496)\end{array}$ \\
\hline ( & & $\begin{array}{l}-0.635 \\
(3.494)\end{array}$ & & $\begin{array}{l}-0.650 \\
(3.498)\end{array}$ \\
\hline HEALTH PERCEPTION 1Y & & $\begin{array}{l}-0.667 \\
(0.468)\end{array}$ & & $\begin{array}{l}-0.635 \\
(0.471)\end{array}$ \\
\hline HEALTH PERCEPTION 2M & & $\begin{array}{l}0.0383 \\
(0.545)\end{array}$ & & $\begin{array}{l}0.0468 \\
(0.547)\end{array}$ \\
\hline HEALTH ISSUE & & $\begin{array}{c}1.581 \\
(1.369)\end{array}$ & & $\begin{array}{c}1.710 \\
(1.375)\end{array}$ \\
\hline EXERCICE & & $\begin{array}{c}0.530^{* *} \\
(0.244)\end{array}$ & & $\begin{array}{c}0.546^{* *} \\
(0.245)\end{array}$ \\
\hline CLEAN TIME & & $\begin{array}{c}0.449^{* * *} \\
(0.145)\end{array}$ & & $\begin{array}{c}0.469^{* * *} \\
(0.146)\end{array}$ \\
\hline HOME WORKING & & $\begin{array}{c}1.111 \\
(1.080)\end{array}$ & & $\begin{array}{c}1.292 \\
(1.096)\end{array}$ \\
\hline MLENGHOME & & $\begin{array}{c}-2.436^{*} \\
(1.443)\end{array}$ & & $\begin{array}{c}-2.450^{*} \\
(1.457)\end{array}$ \\
\hline FLENGHOME & & $\begin{array}{c}3.282^{* *} \\
(1.532)\end{array}$ & & $\begin{array}{c}3.398^{* *} \\
(1.541)\end{array}$ \\
\hline URBAN & & $\begin{array}{l}1.198^{* *} \\
(0.512)\end{array}$ & & $\begin{array}{l}1.141^{* *} \\
(0.515)\end{array}$ \\
\hline COHORT RANKING & & $\begin{array}{c}-1.129^{*} \\
(0.583)\end{array}$ & & $\begin{array}{c}-1.184^{* *} \\
(0.588)\end{array}$ \\
\hline COHORT WEIGHT & & $\begin{array}{c}-0.00201 \\
(0.00506)\end{array}$ & & $\begin{array}{l}-0.00126 \\
(0.00508)\end{array}$ \\
\hline Regional FE & Yes & Yes & Yes & Yes \\
\hline Observations & 13024 & 7711 & 12874 & 7631 \\
\hline R2 Adjusted & 0.00584 & 0.0294 & 0.00662 & 0.0295 \\
\hline F Test & 0.00584 & 0.0294 & 0.00662 & 0.0295 \\
\hline
\end{tabular}

Note: This table estimates the impact of gestational age and birth weight on time investment.

The dependent variable is the parental time investment variable.

All estimations contain wave and regional fixed effect?

Standard errors (in parenthesis)

Statistical significance is denoted by: ${ }^{*} p<0.10,{ }^{* *} p<0.05,{ }^{* * *} p<0.01$ 
The next section estimates the effect of gestational age and birth weight on child development with respect to socioeconomic characteristics.

\subsection{The impact of health on early child development with respect to socioeconomic characteristics}

Given that we have found an effect of health at birth on child development, we now turn our attention to the impact of health on child development concerning the family's socioeconomic status. We explore whether there is evidence that the impact of health at birth on child development differs based on parental income or education when used as proxy for socioeconomic status. Shiko and Eskil (2019) highlighted the importance of exploring the potential differential consequences of health at birth on child development. This offers insight into the mechanism behind the estimated effects of birth health status.

Figures 5 and 6 show the estimated coefficient of the impact of gestational age or birth weight on early child development by decile of revenue and level of education. They are estimates drawn from models applied separately without control variables for each decile of income or educational level. The objective was to determine some correlational statistics before using the interaction models. Figure 5 shows that coefficients are slightly different regarding decile of revenue although not significant. As shown in Figure 6, the impact of health at birth on child development is also nearly similar to education's.

The figures show that poor neonatal health may not disproportionately affect children growing up in high socioeconomic status families compared to children in lower socioeconomic classes. 
Figure 5: Estimated coefficient of the impact of gestational age and birth weight on early child development by decile of revenue
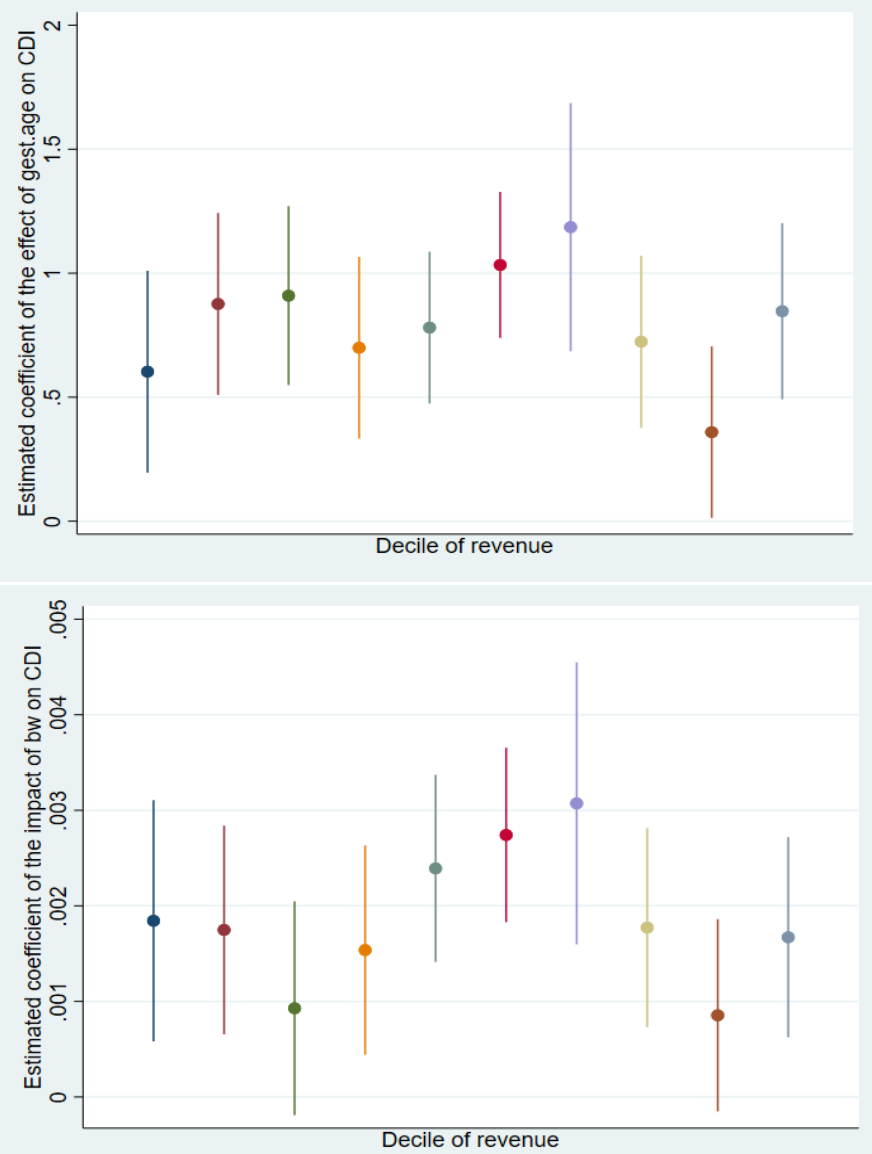

Note: The horizontal axis shows deciles of revenue (REVENUE). The vertical axis shows the estimated coefficient of the impact of gestational age or birth weight on early child development for each decile.

To explore these potential sources of heterogeneity in the effect of birth health status on early development, we analysed in line with Currie and Stabile (2003) and Wei and Feeny (2019) by adding an interaction term in the regression. We included the interaction of birth health and parental income and birth health and mothers' education.

Following theoretical predictions, all else being equal, the effect of health at birth on child development for high-income/educated households may be lower, more significant, or identical to that of low-income/educated households. All configurations are possible depending on the complementarity of inputs. Table 5 shows the estimated coefficient of the impact of gestational age or birth weight on early child development with interaction terms.

Columns 1 and 2 of Table 5 show the estimates of the impact of gestational age in- 
Figure 6: Estimated coefficient of the impact of gestational age and birth weight on early child development by level of education

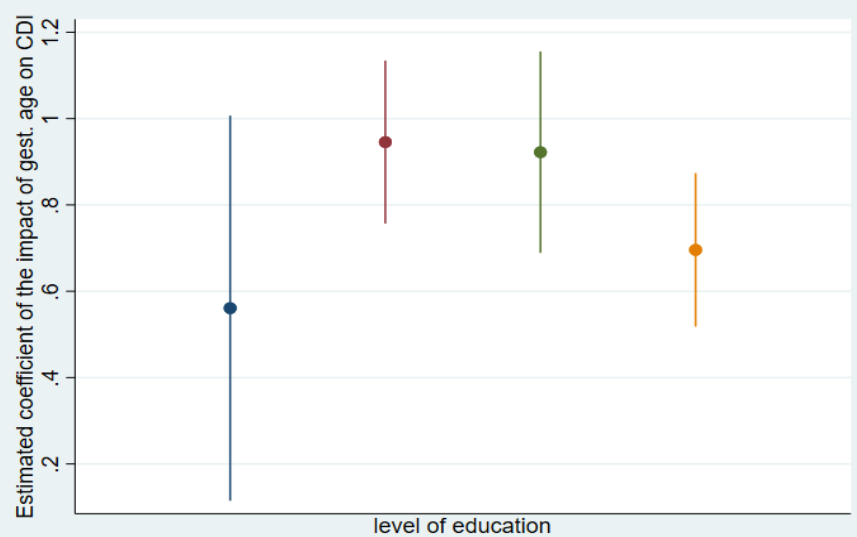

$\square$

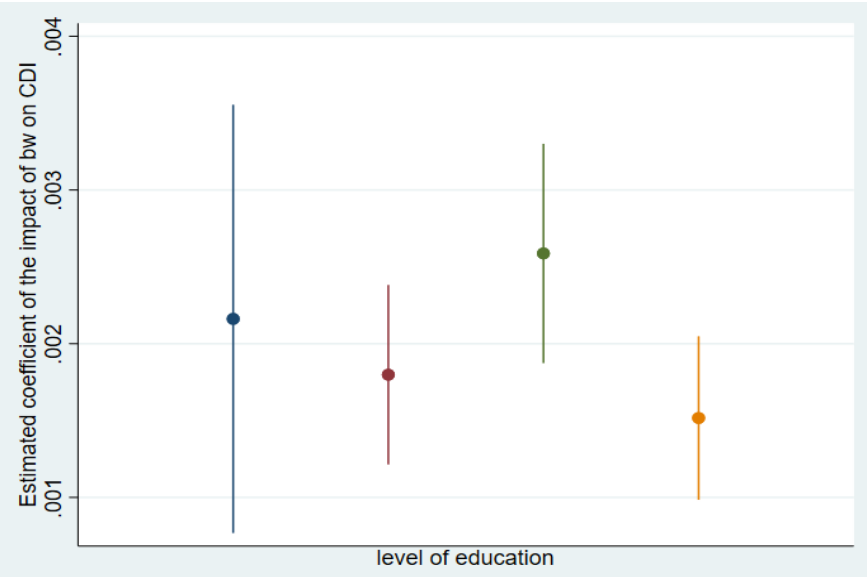

Note: The horizontal axis shows four level of education with respect to the MEDUC variable. The vertical axis shows the estimated coefficient of the impact of gestational age or birth weight on early child development for each subsample of education. 
teracting with revenue using OLS and IV estimation, respectively. Columns 3 and 4 show the estimates of gestational age's impact interacting with education. In Columns 5 to 8 the same exercise was repeated for birth weight. Analogous to Figures 5 and 6 , we once again found no significantly different effects of health at birth on child development with respect to the level of parental revenue or the level of mother's education. Again, we found a positive coefficient for gestational age in the OLS estimation and a lack of significance for birth weight. 


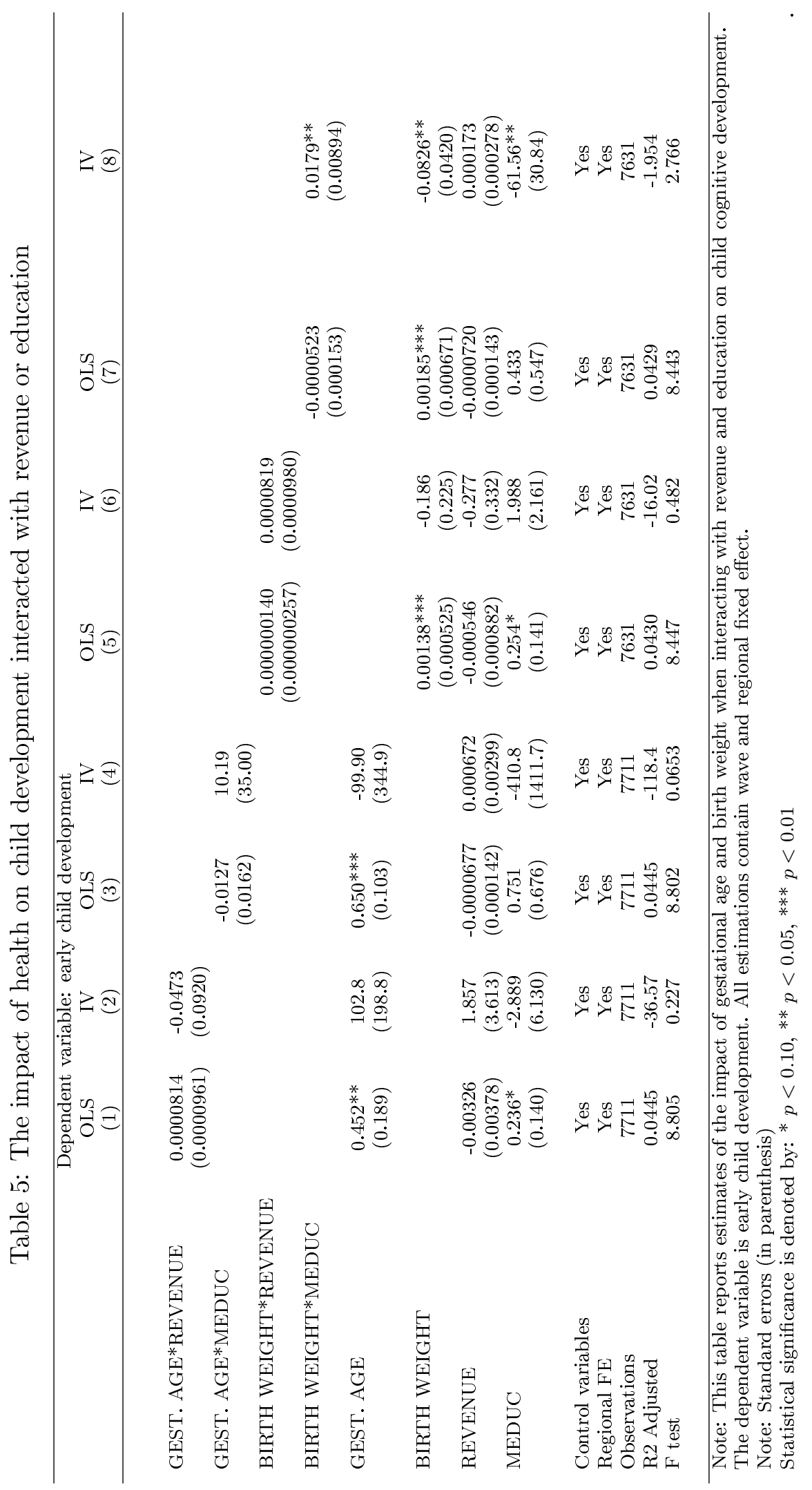


The results indicate that the effects of health at birth are roughly the same for children from different socioeconomic classes. Our findings suggest that, in France, there are no disparities among very young children concerning the consequences of poor health status at birth. They also indicate that, despite potentially different family environments, treating health issues at birth prevents an increase in socioeconomic inequality. Access to health care and medical practices in France for young children appears equal.

It is widely accepted that child development is not an exclusively familial matter. There is space for policy intervention to improve it and address the unequal distribution of initial endowment across the population. Our analysis supports this statement given the positive effect of health at birth on future child development. In this sense, our results support the "1000 first days" strategy of the French Government, which included public action during the prenatal period to improve health outcomes at birth.

\section{Conclusion}

We used an OLS and an IV estimation approach, based on the season of birth, to identify the impact of health at birth on France's human capital. The analysis was conducted on the child level controlling for a wide set of child characteristics and regional fixed effects. The results provide the first estimation of health's impact at birth on early child development at the national level in France. Estimation results indicate an increase of one week in gestational age at birth increases the average early child development at one year of age by $0.6 \%$. Combining empirical and theoretical approaches allowed us to underline that this positive and statistically significant effect is mainly biological. Parental behaviour does not play an essential role in the relationship between health at birth and child development as poor health status is not determined by the time parents spend with their children. This paper's additional contribution consists of distinguishing the effect of health at birth on human capital concerning parents' level of income and education. Our results showed no differential effect among socioeconomic factors suggesting an efficient treatment of health issues at a very early age in France. Redistributive health care systems in France, ensuring equal access to care, may explain this result.

As health at birth was identified as a determinant of child development, our study emphasises the need to identify the determinants of potential factors that cause unequal 
health at birth and design policies to address these inequalities. Air pollutant exposure could be one such factor ${ }^{25}$ Public policies aimed at addressing air pollution issues would thus have beneficial effects on human capital at later ages and its distribution across society. Public investment to reduce perinatal health inequalities and reinforce accessibility of maternity services, particularly in rural areas, is also an important lever 26 A logical direction for further research would be to further explore such policy implications in more depth.

The findings of this study must be seen in the light of some limitations. Possible measurement errors on key CD or health variables may exist. Missing data may point towards selection bias, but we can state that we observed a very low correlation between income and non-responses to the questions used to build the child development index. Our data on the family's characteristics may also have excluded unobservable behavioural variables, which prevents us from examining our instrument's exogeneity condition. Finally, it is essential to underline that the ELFE cohort study has only been conducted once. The data do not allow us to perform a relevant dynamic analysis to examine the relationship between unfavourable health at birth and early child development across time.

\footnotetext{
${ }^{25}$ According to Currie 2009 or Graff Zivin and Neidell 2013, children from lower socioeconomic households were found to be more vulnerable to pollution.

${ }^{26}$ Combier et al. 2013 showed that long travel times, due to the closest maternity units in rural France being far, were associated with an increase in the risk of poor perinatal outcomes.
} 


\section{Appendix}

\section{1 child development}

To select questions of the ELFE cohort relevant to build the child development index, we use the methodology of Ireton (1992). Ireton (1992) provides a list of questions to appreciate the child development during the first year of life:

Table 6: Child development inventory based on the methodology of Ireton (1992)

Interested in his(her) image in a mirror.

Greets people with "Hi" or similar expression.

Feeds self a cookie.

Picks up a spoon by the handle.

Removes socks.

Chews food.

Drinks in a glass/cup.

Sits without help.

Stands steady without support.

Stands up without help.

Sidesteps around furniture or crib while holding on. Or walks.

Walks without help.

Picks up objects with one hand.

Holds two objects at the same time, one in each hand.

Uses two hands to pick up large objects.

Picks up small objects, using thumb and one finger.

Transfers objects from one hand to the other.

Builds a tower of two or more blocks.

Makes sounds like he(she) is talking in sentences. Or used to.

Jabbers.

Points to things.

Calls his(her) parents "Mama" or "Dada" or similar name.

Understands "No"; stops.

Responds to his(her) name.

Imitates some sounds that parents make. Or used to.

Comes when called.

Waves "bye-bye" or good-by.

Hands a toy to parents when asked.
SOCIAL SCALE

SOCIAL SCALE

SELF HELP SCALE

SELF HELP SCALE

SELF HELP SCALE

SELF HELP SCALE

SELF HELP SCALE

GROSS MOTOR SCALE

GROSS MOTOR SCALE

GROSS MOTOR SCALE

GROSS MOTOR SCALE

GROSS MOTOR SCALE

FINE MOTOR SCALE

FINE MOTOR SCALE

FINE MOTOR SCALE

FINE MOTOR SCALE

FINE MOTOR SCALE

FINE MOTOR SCALE

EXPRESSIVE LANGUAGE SCALE

EXPRESSIVE LANGUAGE SCALE

EXPRESSIVE LANGUAGE SCALE

EXPRESSIVE LANGUAGE SCALE

LANGUAGE COMPREHENSION SCALE

LANGUAGE COMPREHENSION SCALE

LANGUAGE COMPREHENSION SCALE

LANGUAGE COMPREHENSION SCALE

LANGUAGE COMPREHENSION SCALE

LANGUAGE COMPREHENSION SCALE 
Table 7: Robustness checks

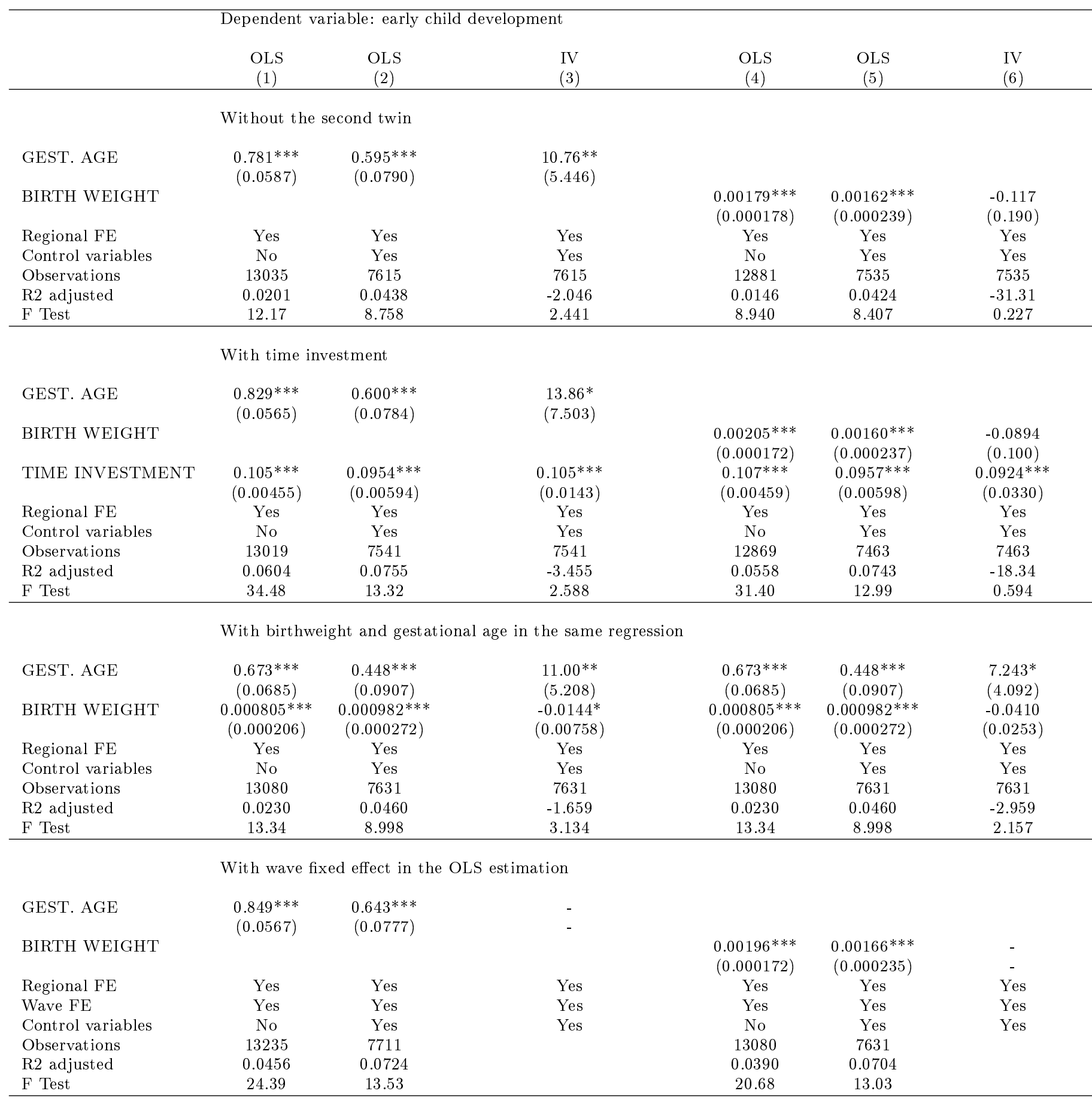

Note: This table varies the specification of the model to look at the impact of gestational age and birth weight on cognitive development.

The dependent variable is the Early child development. All estimations contain regional fixed effect.

Standard errors (in parenthesis)

Statistical significance is denoted by: $* p<0.10,{ }^{* *} p<0.05, * * * p<0.01$ 
Table 8: Subcategories

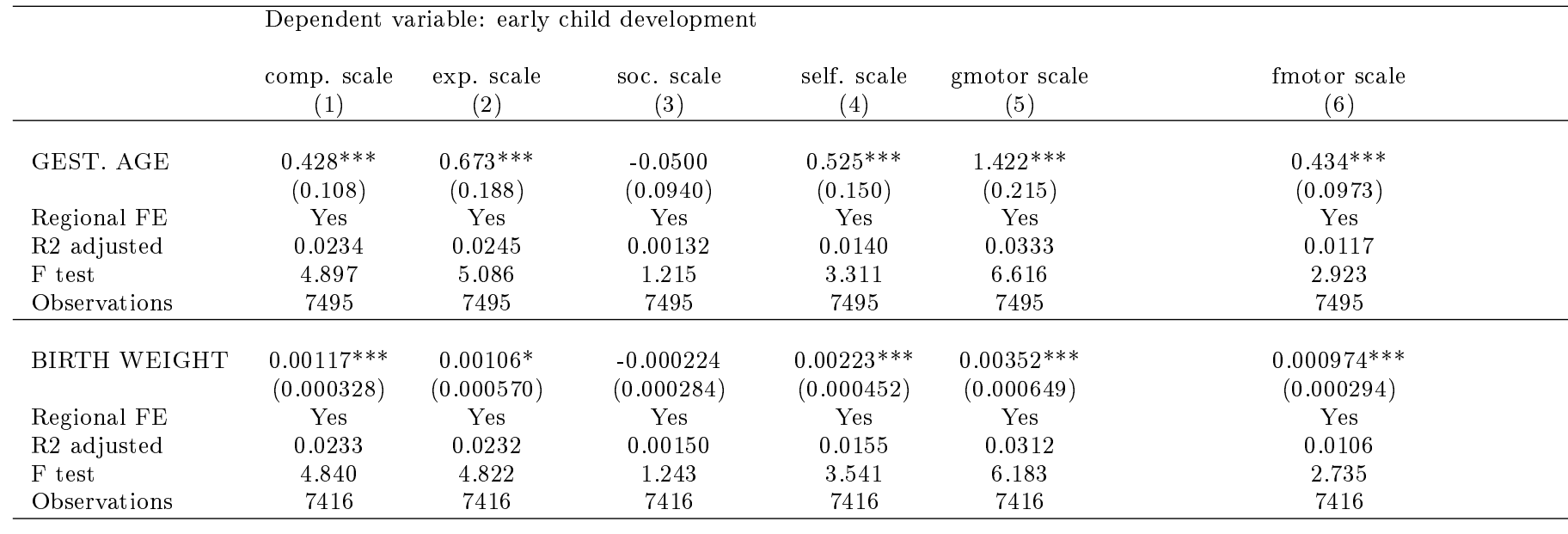

Note: This table varies the specification of the model to look at the impact of gestational age and birth weight on cognitive development. The dependent variable is the Early child development. All estimations contain regional fixed effect.

Standard errors (in parenthesis)

Statistical significance is denoted by: $* p<0.10,{ }^{* *} p<0.05, * * * p<0.01$

\section{References}

D. Almond and J. Currie. Killing me softly: The fetal origins hypothesis. Journal of economic perspectives, 25(3):153-72, 2011b.

D. Almond, J. Currie, and V. Duque. Childhood circumstances and adult outcomes: Act ii. Journal of Economic Literature, 56(4):1360-1446, 2018.

G. S. Becker. A theory of the allocation of time. The Economic Journal, 75(299):493-517, 1965.

G. S. Becker. Health as human capital: Synthesis and extensions. Oxford Economic Papers, $59(3): 379-410,2007$.

P. Bharadwaj, J. P. Eberhard, and C. A. Neilson. Health at birth, parental investments, and academic outcomes. Journal of Labor Economics, 36(2):349-394, 2018.

F. Broner, P. Bustos, and V. M. Carvalho. Sources of Comparative Advantage in Polluting Industries. (18337), 2012.

K. S. Buckles and D. M. Hungerman. Season of birth and later outcomes: Old questions, new answers. The Review of Economics and Statistics, 95(3):711-724, 2013. 
A. Case, D. Lubotsky, and C. Paxson. Economic status and health in childhood: The origins of the gradient. American Economic Review, 92(5):1308-1334, 2002.

M. A. Charles, X. Thierry, J.-L. Lanoe, C. Bois, M.-N. Dufourg, R. Popa, M. Cheminat, C. Zaros, and B. Geay. Cohort profile: The french national cohort of children elfe: birth to 5 years. International Journal of Epidemiology, 30:164 - 175, 2019.

D. Checchi, C. V. Fiorio, and M. Leonardi. Parents' risk aversion and children's educational attainment. Labour Economics, 30:164 - 175, 2014.

Y. Chen and H. Li. Mother's education and child health: Is there a nurturing effect? Journal of Health Economics, 28(2):413 - 426, 2009.

E. Combier, H. Charreire, M. Le Vaillant, F. Michaut, C. Ferdynus, J.-M. Amat-Roze, J.B. Gouyon, C. Quantin, and J. Zeitlin. Perinatal health inequalities and accessibility of maternity services in a rural french region: Closing maternity units in burgundy. Health Place, 24:225 - 233, 2013.

G. Conti, M. Hanson, H. Inskip, S. Crozier, C. Cooper, and K. Godfrey. Beyond Birthweight: The Origins of Human Capital. (13296), 2020.

F. Cunha and J. Heckman. The technology of skill formation. American Economic Review, $97(2): 31-47,2007$.

F. Cunha, J. J. Heckman, and S. M. Schennach. Estimating the technology of cognitive and noncognitive skill formation. Econometrica, 78(3):883-931, 2010.

J. Currie. Healthy, wealthy, and wise: Socioeconomic status, poor health in childhood, and human capital development. Journal of Economic Literature, 47(1):87-122, 2009.

J. Currie. Child health as human capital. Health Economics, 29(4):452-463, 2020.

J. Currie and D. Almond. Chapter 15 - human capital development before age five. Handbook of Labor Economics, 4:1315 - 1486, 2011a.

J. Currie and H. Schwandt. Within-mother analysis of seasonal patterns in health at birth. Proceedings of the National Academy of Sciences, 110(30):12265-12270, 2013. 
J. Currie and M. Stabile. Socioeconomic status and child health: why is the relationship stronger for older children? American Economic Review, 93(5):1813-1823, 2003.

D. Del Boca, C. Flinn, and M. Wiswall. Household choices and child development. Review of Economic Studies, 81(1):137-185, 2014.

E. Del Bono, M. Francesconi, Y. Kelly, and A. Sacker. Early maternal time investment and early child outcomes. The Economic Journal, 126(596):F96-F135, 2016.

D. Dewey, D. E. Creighton, J. A. Heath, B. N. Wilson, D. Anseeuw-Deeks, S. G. Crawford, and R. Sauve. Assessment of developmental coordination disorder in children born with extremely low birth weights. Developmental neuropsychology, 36(1):42-56, 2011.

N. Douthit, S. Kiv, T. Dwolatzky, and S. Biswas. Exposing some important barriers to health care access in the rural usa. Public health, 129(6):611-620, 2015.

M. Duyme and C. Capron. L'inventaire du développement de l'enfant (ide). normes et validation françaises du child development inventory (cdi). Devenir, 22:13-26, 2010.

D. Figlio, J. Guryan, K. Karbownik, and J. Roth. The effects of poor neonatal health on children's cognitive development. American Economic Review, 104(12):3921-55, December 2014 .

D. Figlio, K. Karbownik, J. Roth, M. Wasserman, et al. Family disadvantage and the gender gap in behavioral and educational outcomes. American Economic Journal: Applied Economics, 11(3):338-81, 2019.

M. Francesconi and J. J. Heckman. Child development and parental investment: Introduction. The Economic Journal, 126(596):F1-F27, 2016.

F. Glascoe and P. Dworkin. The role of parents in the detection of developmental and behavioral problems. Pediatrics, 6:829-36, 1995.

J. Graff Zivin and M. Neidell. Environment, health, and human capital. Journal of Economic Literature, 51(3):689-730, 2013.

D. Hryshko, M. J. Luengo-Prado, and B. E. Sørensen. Childhood determinants of risk aversion: The long shadow of compulsory education. Quantitative Economics, 2(1):37$72,2011$. 
H. Ireton. Child development inventory, 1992.

B. Jefferis, C. Power, and C. Hertzman. Birth weight, childhood socioeconomic environment, and cognitive development in the 1958 british birth cohort study. BMJ, 7359(325), 2002.

S. Maggi, L. J. Irwin, A. Siddiqi, and C. Hertzman. The social determinants of early child development: An overview. Journal of Paediatrics and Child Health, 46(11):627-635, 2010 .

R. E. Manuelli and A. Seshadri. Human capital and the wealth of nations. The American Economic Review, 104(9):2736-2762, 2014.

D. O’Neill, S. McGilloway, M. Donnelly, T. Bywater, and P. Kelly Daniel M. A costeffectiveness analysis of the incredible years parenting programme in reducing childhood health inequalities. European Journal of Health Economics, 14:85-94, 2013.

M. Ouidir, J. Lepeule, V. Siroux, L. Malherbe, F. Meleux, E. Rivière, L. Launay, C. Zaros, M. Cheminat, M.-A. Charles, et al. Is atmospheric pollution exposure during pregnancy associated with individual and contextual characteristics? a nationwide study in france. J Epidemiol Community Health, 71(10):1026-1036, 2017.

L. Panico, M. Bartley, Y. J. Kelly, A. McMunn, and A. Sacker. Family structure trajectories and early child health in the uk: Pathways to health. Social Science Medicine, 232:220 $-229,2019$.

M. L. Rowe, N. Denmark, B. J. Harden, and L. M. Stapleton. The role of parent education and parenting knowledge in children's language and literacy skills among white, black, and latino families. Infant and Child Development, 25(2):198-220, 2016.

M. Shiko and H. Eskil. Another look at returns to birthweight. Journal of Health Economics, page 102269, 2019.

L. B. Strand, A. G. Barnett, and S. Tong. The influence of season and ambient temperature on birth outcomes: a review of the epidemiological literature. Environmental research, 111:451-462, 2011.

E. L. Struening, R. Wallace, and R. Moore. Housing conditions and the quality of children at birth. Bulletin of the New York Academy of Medicine, 66(5):463, 1990. 
G. Wehby, M. Ann Marie, and C. Eduardo. The impact of household investments on early child neurodevelopment and on racial and socioeconomic developmental gaps: Evidence from south america. Forum for Health Economics Policy, 14(2), 2012.

L. Wei and D. Feeny. The dynamics of the gradient between child's health and family income: Evidence from canada. Social Science \& Medicine, 226:182-189, 2019. 


\section{CEE-M Working Papers' - 2021}

WP 2021-01

Philippe Mahenc \& Alexandre Volle

«Price Signaling and Quality Monitoring in Markets for

Credence Goods »

WP 2021-02

Mamadou Gueye, Nicolas Quérou, \& Raphael Soubeyran

« Inequality Aversion and the Distribution of Rewards in

Organizations»

WP 2021-03

Lesly Cassin, Paolo Melindi-Ghidi \& Fabien Prieur

"Voting for environmental policy with green consumers:

the impact of income inequality »

WP 2021-04

Marion Davin \& Emmanuelle Lavaine

«The Role Of Health At Birth And Parental Investment In

Early Child Development. Evidence From The French ELFE Cohort»

${ }^{1}$ CEE-M Working Papers / Contact : laurent.garnier@inra.fr

- RePEc https://ideas.repec.org/s/hal/wpceem.html

- HAL https://halshs.archives-ouvertes.fr/CEE-M-WP/ 